\title{
High-Speed (Subsecond) Measurement of Heat Capacity, Electrical Resistivity, and Thermal Radiation Properties of Molybdenum in the Range 1900 to 2800 K*
}

\author{
A. Cezairliyan, M. S. Morse, H. A. Berman, and C. W. Beckett \\ Institute for Materials Research, National Bureau of Standards, \\ Washington, D.C. 20234
}

(October 16, 1969)

\begin{abstract}
A technique is described for the high-speed measurement of heat capacity, electrical resistivity, hemispherical total and normal spectral emittances of electrical conductors at high temperatures (above $1900 \mathrm{~K}$ ) with millisecond resolution. Duration of an individual experiment, in which the specimen is heated from room temperature to close to its melting point, is less than one second. Temperature measurements are made with a high-speed photoelectric pyrometer. Quantities are recorded by a high-speed digital data acquisition system which has a resolution of approximately one part in 8000 . Time resolution of the entire system is $0.4 \mathrm{~ms}$. Results on the above properties of molybdenum in the temperature range 1900 to $2800 \mathrm{~K}$ are reported and are compared with those in the literature. Estimated inaccuracy of measured properties in the above temperature range is: 2 to 3 percent for heat capacity, 0.5 percent for electrical resistivity, 3 percent for hemispherical total emittance and 2 percent for normal spectral emittance.
\end{abstract}

Key words: Electrical resistivity; emittance; heat capacity; high-speed measurements; high temperature; molybdenum; thermal radiation properties; thermodynamics.

\section{Introduction}

Most measurements of heat capacity, electrical resistivity, and various other thermophysical properties at high temperatures employ "drop", steadystate, and quasi steady-state experiments. In all these techniques, the specimen is exposed to high temperatures for relatively long periods of time (minutes-tohours).

When these techniques are extended to very high temperatures (above $2000 \mathrm{~K}$ ), many problems are created as the result of increased heat transfer, chemical reactions, evaporation, diffusion, loss of mechanical strength, etc., and these limit their application. Consequently, it has become necessary to develop a dynamic method which permits the heating of the specimen and the measurement of the pertinent quartities in a very short time. With this method the contributions of most of the phenomena which limit the application of conventional techniques at very high temperatures become negligible.

In recent years, considerable progress has been made in high-speed thermodynamic measurement imethods and related instrumentation techniques. A general review of these is given in $[10]^{1}$.

*This work was supported in part by the Propulsion Division of the U.S. Air Force Office of Scientific Research under contract ISSA-69-0001.

${ }^{1}$ Figures in brackets indicate the literature references at the end of this paper.
Over the past 50 years several investigators $[6,8$, $21,37,40,41,47,49-55,65,69,70,72]$ have developed dynamic and quasi-dynamic techniques for the measurement of heat capacity of electrical conductors. They differ considerably depending on the pulse power source and the method of measurement of specific quantities. In general, either batteries or capacitors have been used as the pulse power source. In most cases, power imparted to the specimen was obtained from pulse current and voltage measurements. The temperature of the heating specimen was either measured by thermocouples or was determined from dynamic electrical resistivity measurements. Use of thermocouples has several limitations and is not applicable to very high-speed work. The electrical resistivity method requires a separate steady-state determination of the electrical resistivity of the specimen as a function of temperature. A dynamic experiment of preliminary nature where a photomultiplier was used for the measurement of specimen temperature was described in [12]. In all of the recent investigations, with one exception [37], oscilloscopic techniques have been employed for the high-speed recording of quantities. Most of the experiments reported in the literature which utilized dynamic techniques were exploratory and were confined to temperatures below $1500 \mathrm{~K}$.

In the present study, a technique is described for 
the dynamic measurement of heat capacity, electrical resistivity, hemispherical total emittance, and normal spectral emittance of electrical conductors at high temperatures (above $1900 \mathrm{~K}$ ). Duration of an individual experiment, in which the specimen is heated from room temperature to close to its melting point, is less than $1 \mathrm{~s}$. A millisecond resolution photoelectric pyrometry technique was employed for the temperature measurements. The dynamic recording of quantities was made with a high-speed, multichannel, digital data acquisition system which has a capability of recording data with $0.4 \mathrm{~ms}$ resolution. A distinct advantage of the present system is that it provides the capability of measuring several properties simultaneously. Experiments were conducted on molybdenum to measure the properties enumerated above over the temperature range 1900 to $2800 \mathrm{~K}$.

\section{Description of the Method}

\subsection{General Description}

The dynamic method employed in this study is based upon rapid resistive heating of the specimen by a single pulse (subsecond duration) of direct current and measuring the pertinent quantities with millisecond resolution. Heat capacity and electrical resistivity are calculated from data obtained during the pulse heating period. Because of the short duration of the experiment, the only significant heat loss is that due to thermal radiation. Data taken during the initial free cooling period following the heating period enables one to compute hemispherical total emittance and thus apply a correction to heat capacity for the radiation heat loss. From separate dynamic experiments, in which radiation from the surface of the specimen is measured in addition to its temperature, normal spectral emittance is obtained. In the following paragraphs the formulation of the relationships between various variables is presented.

\subsection{Formulation of Equations}

a. Heating Period

The power balance for the specimen during the heating period can be expressed as

$$
\text { Power Imparted }=\text { Power Stored }+ \text { Power Losses. }
$$

In high temperature dynamic experiments of millisecond resolution the major source of power loss is that due to thermal radiation. Using the proper quantities, the above relation becomes

$$
\mathrm{ei}=c_{p} n(d T / d t)_{h}+\epsilon \sigma A_{s}\left(T^{4}-T_{e}^{4}\right)
$$

where

$e=$ potential difference across the effective specimen in $\mathrm{V}$

$i=$ current through the specimen in A $c_{p}=$ heat capacity in $\mathrm{J} \mathrm{mol}^{-1} \mathrm{~K}^{-1}$

$n=$ effective amount of specimen in mol

$\epsilon=$ hemispherical total emittance

$\sigma=$ Stephan-Boltzmann constant $\left(5.6697 \times 10^{-8} \mathrm{~W}\right.$ $\mathrm{m}^{-2} \mathrm{~K}^{-4}$ )

$A_{s}=$ effective surface area in $\mathrm{m}^{2}$

$T=$ specimen temperature in $\mathrm{K}$

$T_{e}=$ room temperature in $\mathrm{K}$ $(d T / d t)_{h}=$ heating rate in $\mathrm{K} \mathrm{s}^{-1}$.

Solving eq (1) for $c_{p}$ one obtains

$$
c_{p}=\frac{e i-\epsilon \sigma A_{s}\left(T^{4}-T_{e}^{4}\right)}{n(d T / d t)_{h}} .
$$

\section{b. Cooling Period}

The power balance for the specimen during the initial cooling period can be written as

$$
\text { Power Loss }=\text { Power Radiated }
$$

which can be expressed as

$$
-c_{p} n(d T / d t)_{c}=\epsilon \sigma A_{s}\left(T^{4}-T_{e}^{4}\right)
$$

where

$$
(d T / d t)_{c}=\text { cooling rate in } \mathrm{K} \mathrm{s}^{-1} .
$$

Solving eq (3) for $c_{p}$ one obtains

$$
\begin{aligned}
& c_{p}=\frac{\epsilon \sigma A_{s}\left(T^{4}-T_{e}^{4}\right)}{-n(d T / d t)_{c}} . \\
& \text { c. Relations for Properties }
\end{aligned}
$$

Combination of eqs (2) and (4) yields

$e i=\epsilon \sigma A_{s}\left(T^{4}-T_{e}^{4}\right)-\epsilon \sigma A_{s}\left(T^{4}-T_{e}^{4}\right)\left[\frac{(d T / d t)_{h}}{(d T / d t)_{c}}\right]$.

Defining,

$$
M=-\frac{(d T / d t)_{h}}{(d T / d t)_{c}}
$$

and substituting eq (6) in eq (5) and solving for $\epsilon$ one obtains

$$
\epsilon=\frac{e i}{\sigma A_{s}\left(T^{4}-T_{e}^{4}\right)(1+M)} .
$$

Equation (7) is used to compute values for hemispherical total emittance, $\epsilon$, at selected temperatures which are used to obtain a function for $\epsilon$ in terms of temperature. Then $\epsilon$ values from this function are substituted in eq (2) to obtain heat capacity over the entire temperature range. 
Electrical resistivity is calculated with the aid of the equation

$$
\rho=\frac{R A_{c}}{l}
$$

where

$$
\begin{aligned}
\rho & =\text { electrical resistivity in } \Omega \mathrm{m} \\
R & =\text { resistance of effective specimen in } \Omega \\
A_{c} & =\text { effective cross-sectional area in } \mathrm{m}^{2} \\
l & =\text { effective length in } \mathrm{m} .
\end{aligned}
$$

Normal spectral emittance is calculated by the relation

$$
\epsilon_{N, \lambda}=\frac{L_{s}}{L_{b}}
$$

where

$$
\begin{aligned}
L_{b}= & \text { blackbody radiance from sighting hole in } \\
& \text { specimen as observed by the pyrometer, } \\
L_{s}= & \text { radiance from surface of specimen as } \\
& \text { observed by the pyrometer. }
\end{aligned}
$$

In all the above equations geometrical quantities are corrected for the fact that a sighting hole is present; quantities related to radiation from the sighting hole are corrected for scattered light and departure from blackbody conditions.

\section{Description of the System}

The system used in this study consists of an electric power pulsing circuit and associated high-speed measuring circuits. The pulsing circuit includes the specimen in series with a battery bank, a variable resistance, a shunt (standard resistance), and a fast-acting switch. The high-speed measuring circuits include detectors, an analog-to-digital converter, a core memory, and other related equipment and circuitry necessary for the dynamic measurement and recording of the pertinent quantities. A functional diagram of the complete system is presented in figure 1 . A photograph of the experiment chamber and the high-speed pyrometer is given in figure 2 .

\subsection{Specimen and Experiment Chamber}

The specimen upon which the pulse experiments were made is a tube of the following nominal dimensions: length $=4$ in $(101.6 \mathrm{~mm})$, outside diameter $=0.25$ in $(6.35 \mathrm{~mm})$, wall thickness $=0.02$ in $(0.51 \mathrm{~mm}) . \bar{A}$ ismall rectangular hole ( $1.09 \mathrm{~mm}$ long, $0.56 \mathrm{~mm}$ wide) was fabricated in the wall at the middle of the specimen to approximate blackbody conditions. Potential probes were molybdenum knife edges each at a distance of $12.7 \mathrm{~mm}$ from the end clamps. The knife edges defined an "effective" portion of the specimen which should be free of axial temperature gradients for the duration of the experiment. A schematic diagram showing the arrangement of the specimen, clamps, and potential probes is presented in figure 3 . Thermocouples are connected (electrically insulated) to the two end clamps to measure the specimen temperature before each pulse experiment. The chamber is designed for conducting experiments with the specimen either in vacuum or in a controlled atmosphere.

\subsection{Pulsing Circuit}

The power supply for the pulse heating of the specimen is a $28 \mathrm{~V}$ heavy-duty battery bank. A seriesconnected, water-cooled, variable resistance enables one to adjust the main current and thus to control the heating rate. The fast-acting switch is operated by a series of pulse control units which control the pulse length in addition to providing timing pulses to other electronic measuring and recording instruments. A standard resistor $(0.001 \Omega)$ placed in the main circuit is used to measure the heavy pulse current flowing through the specimen.

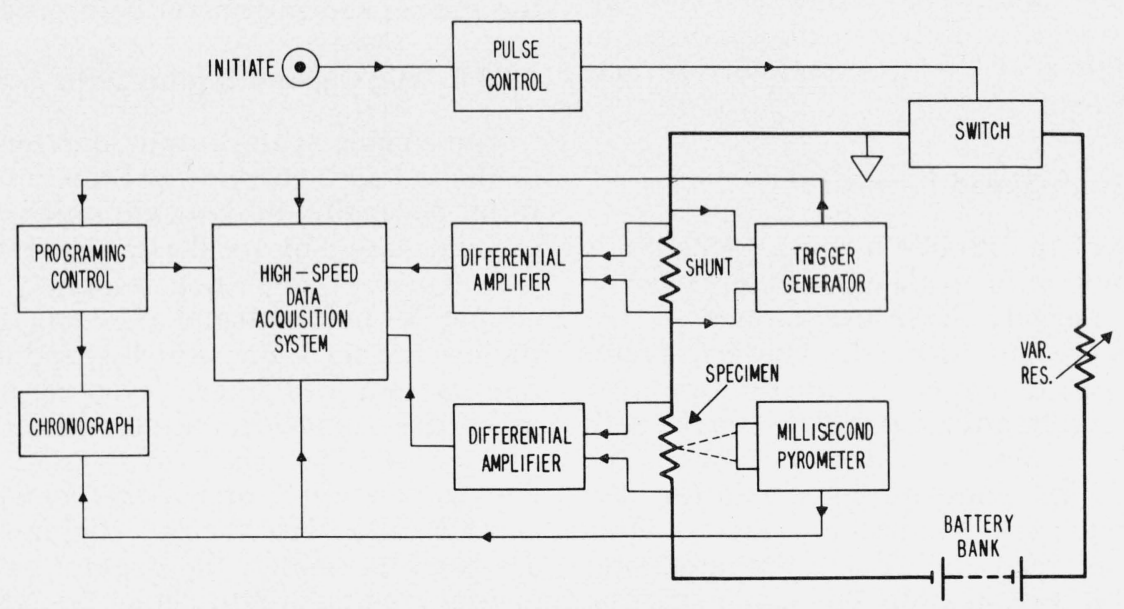

Figure 1. Functional diagram of the complete high-speed measurement system. 


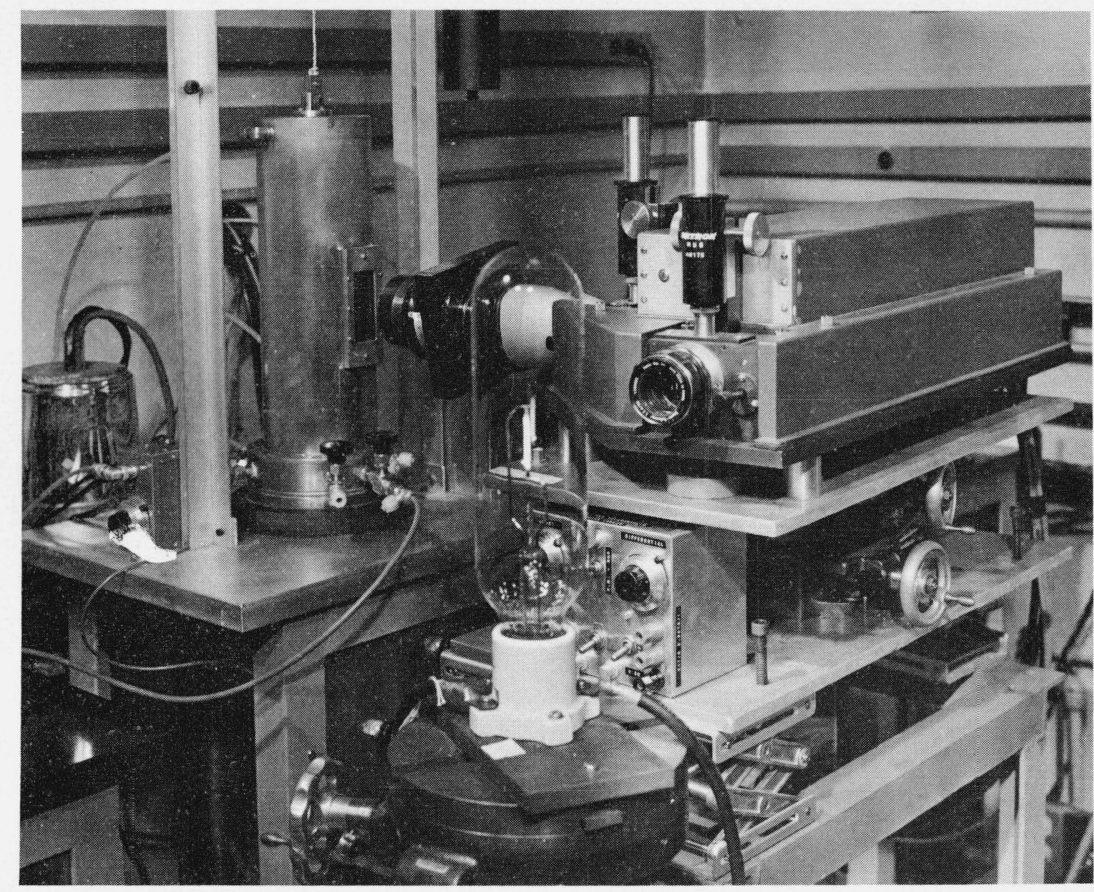

FIGURE 2. Experiment chamber and high-speed pyrometer.

\subsection{Measuring and Control Circuits}

Timing of various events, such as opening and closing of the switch, triggering of various electronic equipment, etc., during a dynamic experiment is achieved by a series of time-delay units. A $400 \mathrm{~Hz}$ synchronous motor used in the high-speed pyrometer provides the time base for the data acquisition system. Voltage signals from both the standard resistor and the specimen are sent to the recording system via differential amplifiers. Triaxial cables are used for the signals to be recorded and coaxial cables for all the controls. A potentiometric system is used to calibrate pulse voltage and pulse current measuring circuits including the differential amplifiers and the digital recording system. A Kelvin bridge is used to measure the resistance of the specimen before and after a pulse experiment.

\subsection{High-Speed Pyrometer}

The temperature of the rapidly heating specimen is measured by means of a high-speed photoelectric pyrometer, which permits 1200 evaluations of the specimen temperature per second. The pyrometer passes a precisely timed sample of radiation from the specimen through an interference filter (wavelength $650 \mathrm{~nm}$, bandwidth $10 \mathrm{~nm}$ ) to a photomultiplier. The anode current of the photomultiplier during the exposure time $(208 \mu \mathrm{s})$ is integrated and the resulting integrator voltage is recorded. Then the integrator is reset to permit it to integrate the anode current due to a similar sample of radiation, which is provided by a calibrated, gas-filled tungsten filament lamp and suitably attenuated by an optical attenuator. Thus, the pyrometer collects the results of an interlaced sequence of exposures to specimen and reference source. Successive exposures to the reference lamp are taken through a sequence of three different optical attenuators mounted on a rotating disc, resulting in a staircase of reference exposures with approximately 50 percent attenuation for each step. This scheme is used for temperature measurements up to $2500 \mathrm{~K}$, the limit of reliable operation of gas-filled lamps. For the measurement of higher temperatures, calibrated optical attenuators are placed in the path of the radiation from the specimen. A manuscript regarding constructional and operational details of the high-speed pyrometer is in preparation [20].

\subsection{High-Speed Digital Data Acquisition System}

The signals at the output of detectors corresponding to the voltage, current, and temperature are in analog form. Normally, in dynamic experiments such signals are measured by oscilloscopic techniques. However, the expected recording accuracy of such methods cannot be better than 1 percent. In order to improve the overall accuracy, a high-speed digital data acquisition system has been designed and constructed to meet the special requirements of the experiments. The system consists of a multiplexer, analog-todigital converter and core memory together with control and interfacing equipment. Oscilloscopes are used to monitor the general pattern of the experimental results, and to detect any anomalies.

All signals are brought to the multiplexer through differential amplifiers in order to avoid the inaccuracies 


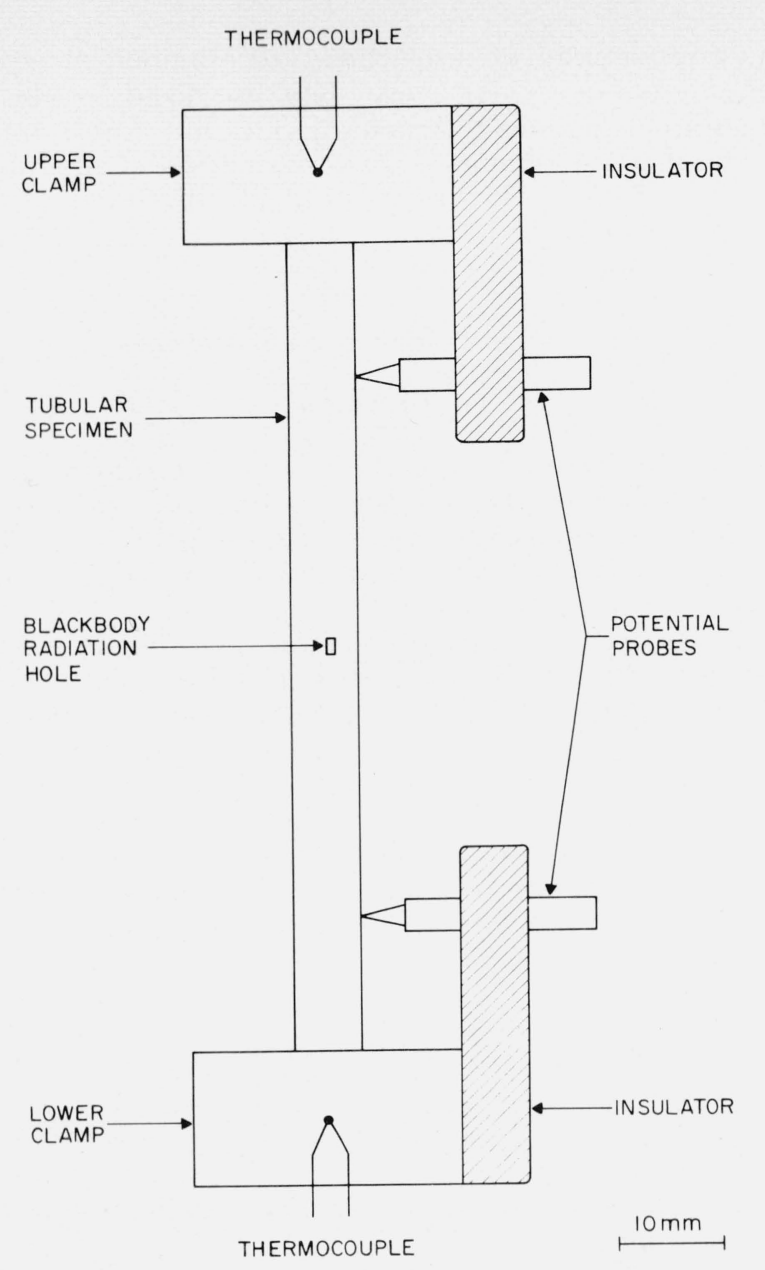

FigurE 3. Schematic diagram showing the arrangement of the specimen, clamps and potential probes.

Potential probes are spring loaded knife edges which are free to move in vertical direction ollow for thermal expansion of the specimen. arising from common ground points. The multiplexed signals go to the analog-to-digital converter, which has a full-scale reading of $\pm 10 \mathrm{~V}$ and a full-scale resolution of one part in $8192\left(8192=2^{13}\right)$. Digital output from the converter consists of 13 binary bits plus a sign bit. This output is stored in a core memory having a capacity of 2048 words of sixteen bits each.

All the above takes place during a dynamic experiment of sub-second duration. After the experiment is over, information stored in the core memory, which is in parallel binary coded form, is converted to serial binary coded decimal form and retrieved in the form of numeric printing and punched paper tape using a teletypewriter. Since the laboratory has access to a remote-control, time-sharing computer, it is possible to unload the memory directly to the computer. This allows one to process the data immediately after an experiment, bypassing the intermediate stage of punching paper tape. A functional diagram of the high-speed data acquisition system is presented in figure 4. A manuscript regarding constructional and operational details of the high-speed digital data acquisition system is in preparation [46].

\section{Measurements on Molybdenum}

\subsection{Procedure in Experimentation}

The temperature interval 1900 to $2800 \mathrm{~K}$ was covered in four ranges with several experiments in each range. This entire set of experiments is referred to as a series. Temperature ranges were as follows:

$$
\begin{array}{ll}
\text { Low: } & 1900-2100 \mathrm{~K} \\
\text { Medium: } & 2000-2280 \mathrm{~K} \\
\text { High: } & 2200-2520 \mathrm{~K} \\
\text { Very High: } & 2400-2800 \mathrm{~K}
\end{array}
$$

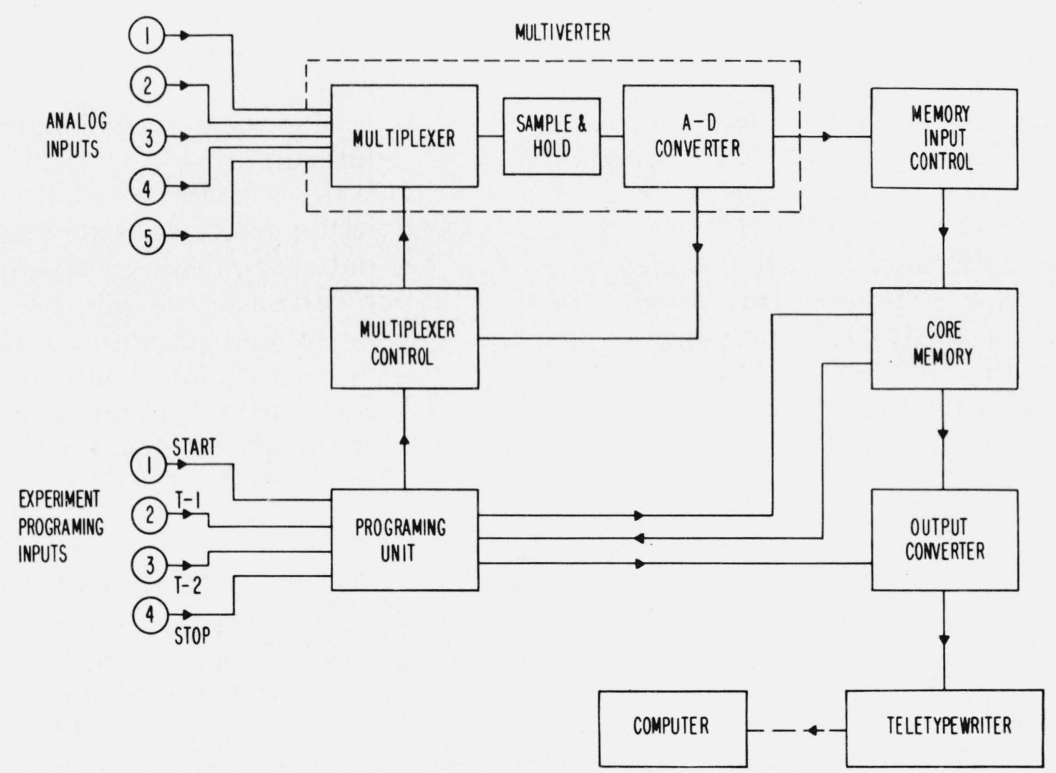

FIGURE 4. Functional diagram of the high-speed data acquisition system. 
The selection of the above temperature ranges was based upon the criterion of optimizing the operation of the pyrometer. In all the experiments the specimen was heated rapidly from room temperature to its respective maximum temperature with a single pulse. The instruments are set at the beginning of an experiment to give information covering the desired temperature range. Two complete series of experiments were conducted on one of the specimens (Mo-1); that is, after the initial series covering the interval 1900 to $2800 \mathrm{~K}$ in four ranges, new experiments were started from $1900 \mathrm{~K}$ and were carried up to $2800 \mathrm{~K}$ in four ranges. To study possible effects arising from different heating rates, two different heating rates, designated as "fast" and "slow", were used in the experiments during the second series. The durations of heating current pulses for "fast" experiments were in the range 270 to $380 \mathrm{~ms}$, depending on temperature level. Heating current pulse durations for "slow" experiments ranged from 540 to $750 \mathrm{~ms}$.

During the first series, six "fast" experiments were conducted for each temperature range. During the second series, two "fast" and four "slow" experiments were made for each range. Two additional experiments were performed in each range for the determination of normal spectral emittance. All of the above experiments (a total of 56) were conducted with the specimen in a low vacuum environment. An experiment, in the medium temperature range, was performed with the specimen in argon environment under atmospheric pressure.

Experiments on the second specimen (Mo-2) were made in the medium temperature range (3 "slow" experiments).

Fourteen separate experiments were performed to determine the magnitude of the scattered light effect in temperature measurements.

Nine pulse experiments around room temperature were made on a calibrated resistance to compare its value measured under dynamic conditions with that measured under steady-state conditions.

The specimen resistance at room temperature was measured with a Kelvin bridge before and after each dynamic experiment. The specimen was weighed before and after the series of experiments in each range.

The pyrometer was calibrated before and after the series of experiments in each temperature range. The standard lamp, used for the pyrometer calibrations, was calibrated against the NBS temperature standard (IPTS 1948) before and after the entire set of experiments. The calibration of amplifiers (for pulse voltage and current measurements), including the entire system of electronic components in the high-speed data acquisition system, was performed three times: before, midway, and after the entire set of experiments.

Other calibrations and checks related to conventional measurement equipment, such as potentiometer, bridge, standard resistance, standard cell, thermocouples, etc., were made before and after the entire set of experiments.

In a dynamic experiment, quantities such as temperature, voltage, current, which are needed for the computation of properties, are obtained at equal time intervals. Then these data are used to obtain quadratic functions for each quantity in terms of time. Properties are computed using the pertinent equations given in section 2.2 with these quadratic functions for the quantities.

\subsection{Directly Measured Quantities}

a. Temperature

The specimen temperature was determined with the high-speed photoelectric pyrometer, which was used as a comparison device between the radiation from a standard lamp and the radiation from the specimen.

Calibration. A calibration was first made under steady-state conditions to determine parameters inherent to the pyrometer, by comparing the radiation of the standard lamp to that of an equivalent reference lamp. These parameters were then used in the determination to compare the reference lamp radiation with the specimen radiation under conditions of rapidly changing temperature. The Wien radiation equation, modified for use with this pyrometer, served as the transfer mechanism:

$$
\frac{1}{T_{X}}=\frac{1}{T_{R}}+A_{R}-A_{X}+\frac{\lambda}{c_{2}} \ln \left(\frac{R+C_{4}}{X+C_{4}}\right)
$$

where

$T_{X}$ is the temperature of the standard lamp (or specimen) in $\mathrm{K}$.

$T_{R}$ is the temperature of the reference lamp in $\mathrm{K}$.

$A_{R}$ is the optical attenuation of the channel through which the reference lamp radiation is received by the pyrometer, in $\mathrm{K}^{-1}$.

$A_{X}$ is the optical attenuation of the channel for the standard lamp (or specimen) radiation, in $\mathrm{K}^{-1}$.

$\lambda$ is the mean wavelength of the interference filter in $\mathrm{m}$.

$c_{2}$ is the second radiation constant, in $\mathrm{mK}$.

$R$ is the arbitrary scale number furnished by the data acquisition system for the radiance received in the reference lamp channel.

$X$ is the corresponding number for the radiance in the standard lamp (or specimen) channel.

$C_{4}$ is a constant inherent in the electronic circuit of the pyrometer, in the same arbitrary scale as $R$ and $X$.

The quantities $A_{R}, A_{X}$, and $C_{4}$ are properties of the pyrometer. They are determined in calibration experiments, in which a standard lamp is substituted for the specimen with the window of the chamber interposed between the lamp and the pyrometer.

The attenuator disk of the pyrometer produces three levels of radiance in the reference channel for each half-revolution of the attenuator, and each un- 
known or standard radiance is sandwiched between two reference radiances. There are, therefore, twelve radiances per revolution, six reference and six unknown. By making three exposures per calibration, one with the standard lamp adjusted to produce a response in the unknown channel nearly equal to that obtained in the reference channel with the largest attenuator opening (smallest attenuation), one with the standard lamp adjusted to a response near that of the smallest attenuator opening, and one near that of the medium attenuator opening, it was possible to calculate all six $A_{X}$ values and all six $A_{R}$ values, and the $C_{4}$ value for each exposure. The redundancy of three separate exposures (36 equations for 15 parameters to be determined) makes it possible to choose those ratios of $R$ and $X$ which give the most accurate values of $A$ and $C_{4}$. Because of the random variation of the radiances in any one exposure, the data from a large number of revolutions (usually 30 ) were averaged before calculating the $A$ values. The standard deviation of an individual radiance from its mean was normally about 0.2 percent, and the standard deviation of the mean was normally about 0.04 percent.

Specimen Temperature. The $A_{R}$ and $A_{X}$ values obtained from the calibration make it possible to calculate the temperature of an unknown specimen placed in the same position that the standard lamp occupied in the calibration, the reference lamp remaining in the reference channel. Equation (10) is now used to obtain $T_{X}$ directly. The quantity $C_{4}$ is calculated separately for each half-revolution by comparing the high-reference radiance (largest attenuation opening) with the low-reference radiance and inserting the corresponding $A_{R}$ values; the temperature terms drop out because " $T_{X} "=T_{R}$. Because of possible pyrometer drift, calculations of a given $T_{X}$ were confined within a half-revolution $(2.5 \mathrm{~ms})$; it was also found that within this time period temperature determinations were most accurate if unknown radiances were calculated against reference radiances nearest in level rather than closest in time. Each unknown temperature was calculated separately from each of the bracketing reference radiances, and the two $T_{X}$ values thus obtained were weighted linearly for their nearness to the respective references and averaged, thus:

$$
T_{X}=\frac{T_{X_{1}}\left(X-R_{2}\right)+T_{X_{2}}\left(R_{1}-X\right)}{R_{1}-R_{2}}
$$

where

$T_{X_{1}}$ is the temperature calculated by eq (10) from reference radiance $R_{1}$.

$T_{X_{2}}$ is similarly obtained from $R_{2}$.

$X$ is the unknown radiance.

$R_{1}, R_{2}$, and $X$ are corrected for $C_{4}$.

In calculating all unknown (specimen) temperatures, corrections were made for (1) scattered light and (2) departure from blackbody conditions (geometrical). The expressions for the correction of both the scattered light effect and departure from ideal blackbody conditions, which are discussed in detail in sections $4.3 \mathrm{a}$ and $4.3 \mathrm{~b}$ below, have essentially the same form; thus, one may combine them from eqs (13) and (16), and obtain the relation

$$
\frac{1}{T_{c}}=\frac{1}{T_{0}}-\frac{\lambda}{c_{2}} \ln \left(\frac{1}{F}\right)
$$

where $T_{0}$ and $T_{c}$ are observed and corrected (both for scattered light and blackbody departure) temperatures, respectively, and the quantity $F=S Q$, the product of the scattered light correction factor and the blackbody quality. Equation (12) was used to correct all observed temperatures.

During a pulse experiment some of the material which evaporated from the specimen deposited on the window of the specimen chamber, causing additional radiance attenuation in the specimen channel of the pyrometer. Thus a calibration made through the window at the end of a series of experiments resulted in higher $A_{X}$ values than before the series. Therefore, two calibrations were made, one before and one after a series of dynamic experiments for a given temperature range, and all $A$ values used for specimen temperature calculation were estimated by linear interpolation between the two sets. Inasmuch as most of the deposited material is evaporated during the relatively long cooling period, the first determination was based directly on the first calibration; the last was interpolated one step short of the final calibration. The window was cleaned after the second calibration.

Temperature determinations beyond the upper limit of the standard lamps were made by inserting an attenuator in the optical path of the specimen radiation, and performing two calibrations, one without and one with the external attenuator. From the $A$ values of the first calibration without the external attenuator and the apparent temperature of the standard lamp through the external attenuator in the second calibration, the attenuation of the external attenuator was determined and added to all the $A_{X}$ values, so that specimen temperatures higher than the standard lamp range could be calculated.

\section{b. Voltage and Current}

Voltages across and currents through the specimen were determined by multiplying the arbitrary scale numbers furnished by the data acquisition system by calibration factors in volts and amperes per recording scale unit. The calibration factors were determined by supplying known voltages to the system in a steadystate condition and averaging 40 such readings for each of 10 different levels between 0 and $10 \mathrm{~V}$. The slope of the linear plot of voltage or current versus unit reading is the calibration factor. The standard deviation of a typical individual voltage reading from the mean at a given level was 0.02 percent, the standard deviation of the mean 0.005 percent, and the standard deviation of the function representing applied voltage vs. reading was 0.01 percent. For current, the corresponding standard deviations were 0.02 percent, 0.005 percent, and 0.03 percent. Three such voltage and current calibrations made during the course of 
the determinations (two months) indicated a small linear drift of each of these calibration factors with time. The calibration factors used for each day were interpolated from the three sets of calibrations. The drift corresponding to each day was 0.0001 percent for voltage and 0.0004 percent for current.

\section{c. Mass}

The mass of the specimen was determined before and after a series of experiments in a given temperature range. The mass to be used for each experiment was calculated by linear interpolation, with the assumption (as in the temperature calibrations) that no mass was evaporated during the heating period of the first experiment in the series. The rate of loss of mass varied from $0.05 \mathrm{mg}(0.001$ percent $)$ per experiment to $0.36 \mathrm{mg}$ (0.008 percent), depending on the temperature range of the experiment.

The effective mass of the specimen was calculated from the total mass by ratio of the surface area between voltage probes to total surface area. Loss of mass during an experiment took place only on the exposed portion of the specimen (between the clamps). A correction to account for this was included in the determination of the effective mass.

\section{d. Dimensions and Density}

The total length, length between clamps, length between probes, outer diameter, and slit and hole lengths were measured at $298 \mathrm{~K}$ with a micrometer microscope to the nearest $0.03 \mathrm{~mm}$. The thickness of cylinder wall was calculated from the mass, surface areas, and density.

Density of molybdenum at $298 \mathrm{~K}$ was obtained by the water displacement method in a pycnometer. The results of four determinations gave a value of $10.21 \times 10^{3} \mathrm{~kg} \mathrm{~m}^{-3}$ with a standard deviation of the mean of 0.02 percent. This compares favorably with the reported values of $10.2 \times 10^{3} \mathrm{~kg} \mathrm{~m}^{-3}$ [33], and $10.22 \times 10^{3} \mathrm{~kg} \mathrm{~m}^{-3}[67]$.

\subsection{Corrections}

Several corrections were made on both observed and derived quantities at different stages of the computations. The small corrections are described in the appropriate places in the text. The most significant corrections are those due to the scattered light effect and departure from blackbody conditions in the computations of temperature, and thermal radiation loss in the computations of heat capacity. The mathematical correction due to thermal radiation loss is presented in section 2.2. In the following paragraphs corrections due to scattered light and departure from blackbody conditions are described.

\section{a. Scattered Light Effect}

The optics of the pyrometer scatter light from regions immediately surrounding the target area into the pyrometer. Since the radiance distribution around the target on the tubular specimen differs from that around the target area on the calibrating lamp, a correction is required.

Temperature correction due to the scattered light effect may be expressed by

$$
\frac{1}{T_{c}}=\frac{1}{T_{0}}-\frac{\lambda}{c_{2}} \ln \left(\frac{1}{S}\right)
$$

where $T_{0}$ and $T_{c}$ are observed and corrected temperatures, respectively, and $S$ is the scattered light correction factor, which is given by

$$
S=\frac{1+\epsilon_{N}{ }_{\lambda} K}{1+K}
$$

where $\epsilon_{N, \lambda}$ is normal spectral emittance, and $K$ is the scattering ratio.

The scattering ratio, $K$, is the fraction of radiation that the pyrometer senses which comes from an area outside the defined target. The parameter $K$ may be expressed by

$$
K=K_{1}-K_{2}
$$

where

$K_{1}=$ total scattered radiation from outside of target $K_{2}=$ scattered radiation from background.

The quantity $K_{1}$ can be obtained experimentally by employing a specimen similar to the one used in dynamic experiments with the exception that the portion of the tube behind the sighting hole is removed. Then, $K_{1}$ is the ratio of radiation from hole to that from surface. The required values were obtained by conducting two experiments, one with the pyrometer aimed at the hole, and another with the pyrometer aimed at the surface.

In the above case, radiation from the hole includes scattered radiation from adjacent surfaces, as well as scattered radiation from the background (chamber wall) as seen through the hole. In order to determine the magnitude of the background radiation, separate experiments were conducted on a specimen composed of two strips ( $3.2 \mathrm{~mm}$ wide) placed parallel to each other with a separation of approximately $4 \mathrm{~mm}$. Since in this arrangement the opening between the strips was large, the contribution of surface scattering was negligible and thus one was able to obtain the scattered radiation from the background. This quantity was then used to correct $K_{1}$ according to eq (15). All of the above described experiments were performed under dynamic heating conditions, and the pyrometer outputs for each pair of experiments were related to each other on the basis of times corresponding to equal resistance values of the specimen.

The results for scattering ratios for two different sighting hole geometries are given in figure 5. It may be seen that they are not dependent on radiation level. Therefore, a constant value for $K(0.0738)$ was assumed for all temperatures for a given specimen. The scatter- 


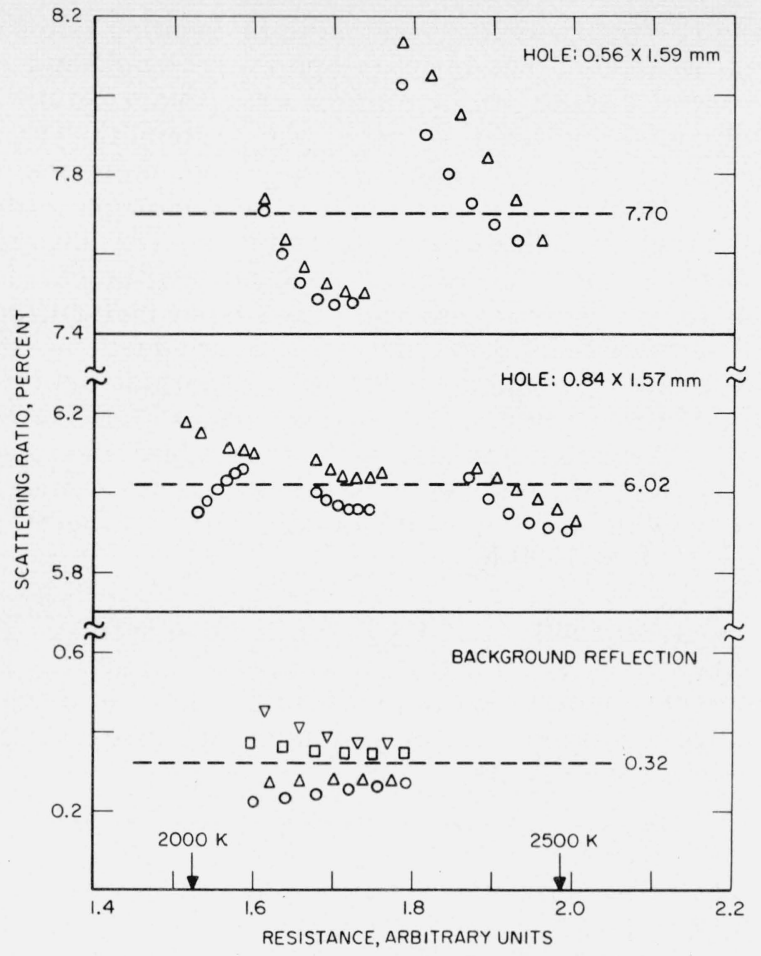

FIGURE 5. Scattering ratio for different size sighting holes.

ing light correction factor, $S$, was obtained as a function of temperature using the measured values of normal spectral emittance as a function of temperature together with the value of $K$, eq (14).

\section{b. Blackbody Quality}

Temperature correction due to departure of the specimen from blackbody conditions may be expressed by

$$
\frac{1}{T_{c}}=\frac{1}{T_{0}}-\frac{\lambda}{c_{2}} \ln \left(\frac{1}{Q}\right)
$$

where $T_{0}$ and $T_{c}$ are observed and corrected temperatures, respectively, and $Q$ is the blackbody quality.

Departure from ideal blackbody conditions (geometrical factor) for the specimen was estimated using DeVos' [15] method. Computations were made assuming perfectly diffuse, perfectly specular, and two intermediate conditions for the internal surface of the tubular specimen. The sighting hole $(0.56 \times 1.09 \mathrm{~mm})$ was $0.79 \mathrm{~mm}$ off-center to improve blackbody conditions. Because of the uncertainty in temperature gradients in the specimen close to the clamps, two sets of calculations were made using two different effective specimen lengths $(50$ and $76 \mathrm{~mm}$ ). Since the variation of the dependence of blackbody quality on internal surface conditions and length of the effective specimen was small ( 0.994 to 0.997$)$, a value of 0.995 was used for $Q$ in all the computations related to the temperature of the specimen with the sighting hole geometry given above.

\subsection{The Molybdenum Specimen}

Molybdenum specimens used were in tubular form with dimensions given in section 3.1. The outer surface of each specimen was polished to reduce heat loss due to thermal radiation.

Specimen characterization was made by the following methods: (1) photomicrographic, (2) chemical analysis, (3) residual resistivity ratio.

Photomicrographs of the specimen before and after the entire set of experiments were prepared. The results on Mo-1 are shown in figure 6. It may be seen that considerable grain growth had taken place as the result of pulse heating of the specimen to high temperatures.

Chemical analyses were made of the specimen before and after the entire set of experiments. Comparison of results does not indicate any detectable change in impurity concentrations. A list of the nature and concentration of impurities in the molybdenum specimen is given in table 1 .

The residual resistivity ratio of the specimen (ratio of electrical resistance at $273 \mathrm{~K}$ to that at $4 \mathrm{~K}$ ) was measured before and after the entire set of experiments. The resistivity ratio before and after are 3.4 and 5.4, respectively, with an uncertainty of \pm 0.05 .
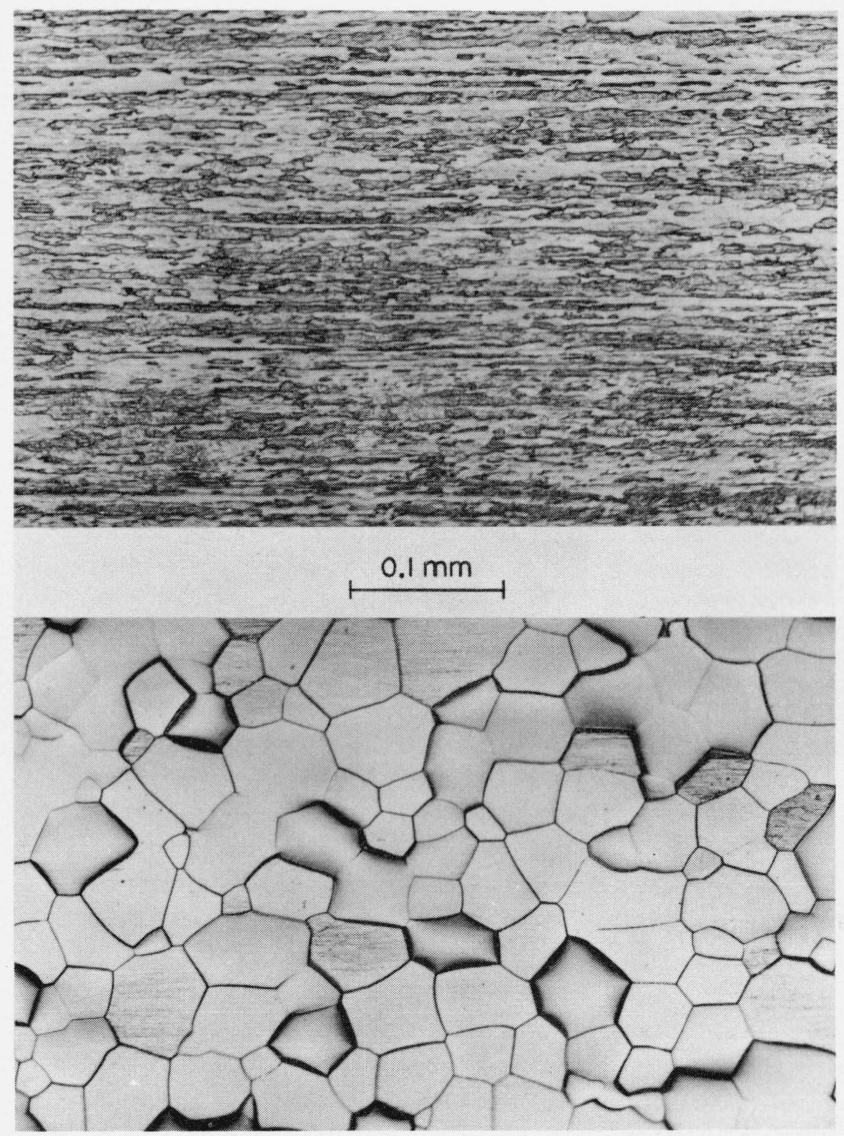

FIGURE 6. Photomicrographs of the molybdenum specimen corresponding to the conditions before (upper photograph) and after (lower photograph) the entire set of experiments. 
TABLE 1. Impurities in molybdenum specimen

\begin{tabular}{c|c}
\hline \hline Impurity & $\begin{array}{c}\text { Composition ppm } \\
\text { (by weight) }\end{array}$ \\
& \\
$\mathrm{Ag}$ & $<10$ \\
$\mathrm{Al}$ & $<10$ \\
$\mathrm{C}$ & 20 \\
$\mathrm{Ca}$ & $<10$ \\
$\mathrm{Co}$ & $<10$ \\
$\mathrm{Cr}$ & 10 \\
$\mathrm{Cu}$ & 100 \\
$\mathrm{Fe}$ & $<10$ \\
$\mathrm{Mg}$ & $<10$ \\
$\mathrm{Mn}$ & $<10$ \\
$\mathrm{Ni}$ & 100 \\
$\mathrm{~N}$ & 10 \\
$\mathrm{O}$ & 40 \\
$\mathrm{Si}$ & $<10$ \\
$\mathrm{Sn}$ & $<10$ \\
$\mathrm{Ti}$ & $<10$ \\
$\mathrm{~W}$ & 80 \\
$\mathrm{Zr}$ & $<100$ \\
& \\
\hline & \\
\hline
\end{tabular}

$360<$ Total $<560$

In addition, the electrical resistance of the specimen was measured at $293 \mathrm{~K}$ under steady-state conditions before and after the entire set of experiments. After correcting for weight losses, the results indicate that the electrical resistivity of the specimen at $293 \mathrm{~K}$ had changed from $5.681 \times 10^{-8} \Omega \mathrm{m}$ to $5.674 \times 10^{-8} \Omega \mathrm{m}$, a decrease of 0.12 percent.

Measurements of the length of the specimen which were made after each set of experiments over the entire temperature range 1900 to $2800 \mathrm{~K}$ do not indicate any permanent elongation (within the measurement resolution of approximately 0.04 percent).

\subsection{Experimental Results on Molybdenum}

\section{a. Normal Spectral Emittance}

Normal spectral emittance measurements were performed on the Mo-1 specimen during the second heating series. The measurements were confined to the effective wavelength $(650 \mathrm{~nm})$ and the effective bandwidth $(10 \mathrm{~nm})$ of the pyrometer interference filter. Since radiation from the surface is approximately one third that from the sighting hole, meaningful data in this case are confined to the upper one third of each temperature range. In order to extend the range of determinations to temperatures compatible with those of heat capacity and electrical resistivity, additional experiments were performed in a temperature range below the "low" range. The experiments consisted of alternate heating runs in which the pyrometer was directed first at the black-body hole in the usual manner and then at the adjacent surface of the specimen. The ratio of radiances measured at equal temperatures is the normal emittance for the effective wavelength of the measurement, provided the hole measurement is corrected for departure from blackbody conditions and any scattered radiation originating from the adjacent surface. Times of equal temperature in the two experiments were found by locating times of equal resistance since the temperatures could not be measured directly in the surface experiment. In order to eliminate partially some of the systematic errors caused by the difference in the time sequence of surface and hole experiments, the following order was adopted: hole-surface-surface-hole. The average of the two sets of normal spectral emittances for each range, which were computed from hole-surface and surface-hole combinations, were used in the final results. A linear function for normal spectral emittance was obtained by least squares approximation of the individual results, with a standard deviation of $6.5 \times 10^{-4}(0.2$ percent $)$. The results are presented in figure 7 . The function, which is valid in the temperature range 1850 to $2800 \mathrm{~K}$, is

$$
\epsilon_{N, \lambda}=0.3540-1.173 \times 10^{-5} T \text { (second series). }
$$

The experimental results (individual points) on normal spectral emittance of molybdenum are given in the appendix (table $\mathrm{A}-3$ ).

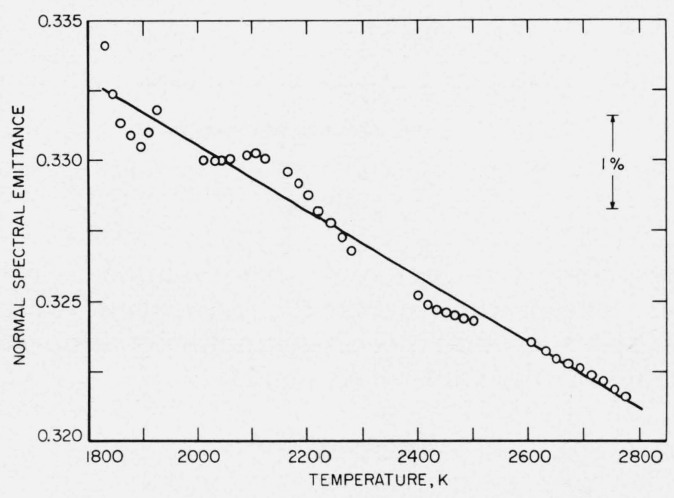

FIGURE 7. Normal spectral emittance of molybdenum at $\lambda=650$ nm (second series).

\section{b. Hemispherical Total Emittance}

Hemispherical total emittance of the $\mathrm{Mo}^{-1}$ specimen was measured during the first and second heating series. Since emittance was determined from data taken during the initial free cooling period, only the upper portion of each temperature range was used. In order to extend the range of determinations to temperatures compatible to those in heat capacity and electrical resistivity, an additional determination for a range below the "low" range was also made.

Temperatures were taken at equal time intervals along the initial cooling curve (approximately the initial $20-40 \mathrm{~K}$ ) and the corresponding instants of time for each temperature were calculated for both the cooling and heating curves. The voltage and current were computed for each instant on the heating curve, and heating and cooling rates from both curves. Emittance could then be computed for each temperature taken by using eq (7). The emittances thus obtained were averaged in each experiment and related to an average temperature. During the first heating series two to three experiments for each temperature range 
were made to yield emittance, while during the second heating series only one experiment for each range was performed. A linear function for hemispherical total emittance for each heating series was obtained by least squares approximation of individual results. Standard deviation of the points from the function for the first and second heating series were $2.5 \times 10^{-3}$ (0.8 percent) and $2.8 \times 10^{-3}$ (1 percent), respectively. The results are presented in figure 8 . The functions which are valid in the temperature range 1900 to 2800 $\mathrm{K}$, are

$$
\begin{aligned}
& \epsilon=0.1424+6.749 \times 10^{-5} T(\text { first series }) \\
& \epsilon=0.1210+7.061 \times 10^{-5} T(\text { second series })
\end{aligned}
$$

The experimental results (individual points) on hemispherical total emittance of molybdenum are given in the appendix (table A-4).

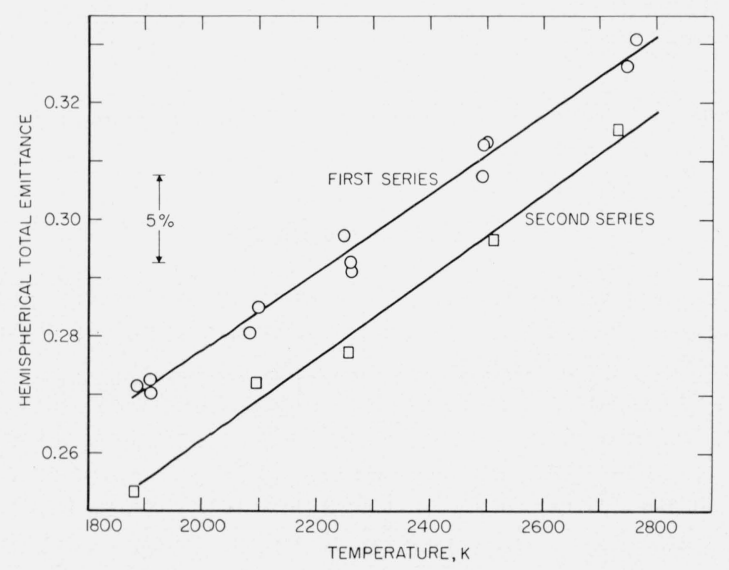

FigURE 8. Hemispherical total emittance of molybdenum

\section{c. Heat Capacity}

The experiments which contributed to the determination of heat capacity of Mo-1 were performed as follows:

First heating series: fast (270-380 ms pulse length), six experiments in each temperature range.

Second heating series: fast $(270-380 \mathrm{~ms}$ pulse length), two experiments in each temperature range.

Second heating series: slow (540-750 ms pulse length), four experiments in each temperature range.

A quadratic function for heat capacity for each temperature range and also for each heating series was obtained by least squares approximation of results from individual experiments. Results corresponding to the very high range in the first series showed a systematic drift with time. Because of this, fits involving data of the very high range gave high standard deviations. Since this range was the only exception, the results in the very high range were not considered in the overall fits for the first series. The following equations were obtained:

$$
\begin{aligned}
& \text { First series }(1900-2520 \mathrm{~K}) \\
& c_{p}=45.19-2.090 \times 10^{-2} T+8.037 \times 10^{-6} T^{2}
\end{aligned}
$$

Second series $(1900-2800 \mathrm{~K})-$ fast

$$
c_{p}=45.80-2.098 \times 10^{-2} T+7.796 \times 10^{-6} T^{2}
$$

Second series $(1900-2800 \mathrm{~K})-$ slow

$$
c_{p}=43.81-1.937 \times 10^{-2} T+7.494 \times 10^{-6} T^{2}
$$

where $T$ is in $\mathrm{K}$ and $c_{p}$ is in $\mathrm{J} \mathrm{mol}^{-1} \mathrm{~K}^{-1}$.

Standard deviations of individual points from these functions are 0.5 percent for eq (20), and 0.3 percent for eqs (21) and (22). The differences between the results of "slow" and "fast" experiments in the second series are given in table 2 . Since in the second series the number of "slow" experiments was twice that of the "fast" experiments and since the average difference between them was within the standard deviation of each set, the results of "slow" experiments were considered as the basis of comparison with the results of the first series. The differences between the results of the first and second heating series are tabulated in table 3. Deviations of individual results from smooth functions for the first and second (slow) heating are presented in figures 9 and 10 , respectively. The experimental results (individual points) on heat capacity of molybdenum for the first and second (slow) series are given in the appendix (tables $\mathrm{A}-1$ and $\mathrm{A}-2$ ).

All the experiments described above were conducted with the Mo-1 specimen in a low vacuum environment. An additional experiment (second series - slow, medium temperature range) was performed with the specimen

TABLE 2. Differences in measured values for heat capacity and electrical resistivity between "slow" and "fast" experiments

\begin{tabular}{c|c|c|c|c}
\hline \multirow{2}{*}{$\begin{array}{c}\text { Temperature } \\
\mathrm{K}\end{array}$} & \multicolumn{2}{|c|}{ Heat Capacity } & \multicolumn{2}{c}{ Resistivity } \\
\cline { 2 - 5 } & $\Delta$ & $\Delta$ & $\Delta$ & $\Delta$ \\
& $\mathrm{J} \mathrm{mol}^{-1} \mathrm{~K}^{-1}$ & $\%$ & $10^{-8} \Omega \mathrm{m}$ & $\%$ \\
\hline & & & & \\
2000 & 0.02 & 0.05 & 0.10 & 0.19 \\
2200 & .09 & .23 & .12 & .20 \\
2400 & .13 & .32 & .11 & .18 \\
2600 & .15 & .34 & .09 & .13 \\
2800 & .14 & .30 & .04 & .05 \\
\hline
\end{tabular}

$\Delta=$ Slow - Fast

TABLE 3. Differences in measured values of heat capacity and electrical resistivity between first and second series

\begin{tabular}{c|c|c|c|c}
\hline \multirow{2}{*}{$\begin{array}{c}\text { Temperature } \\
\mathrm{K}\end{array}$} & \multicolumn{2}{|c|}{ Heat Capacity } & \multicolumn{2}{c}{ Resistivity } \\
\cline { 2 - 5 } & $\Delta$ & $\Delta$ & $\Delta$ & $\Delta$ \\
& $\mathrm{J} \mathrm{mol}^{-1} \mathrm{~K}^{-1}$ & $\%$ & $10^{-8} \Omega \mathrm{m}$ & $\%$ \\
\hline & & & & \\
1900 & 0.43 & 1.26 & 0.24 & 0.48 \\
2000 & .49 & 1.39 & .29 & .55 \\
2100 & .56 & 1.54 & .36 & .64 \\
2200 & .64 & 1.70 & .44 & .74 \\
2300 & .73 & 1.87 & .53 & .86 \\
2400 & .83 & 2.05 & .64 & .98 \\
2500 & .94 & 2.23 & .76 & 1.12 \\
\hline
\end{tabular}

$\Delta=$ First - Second 


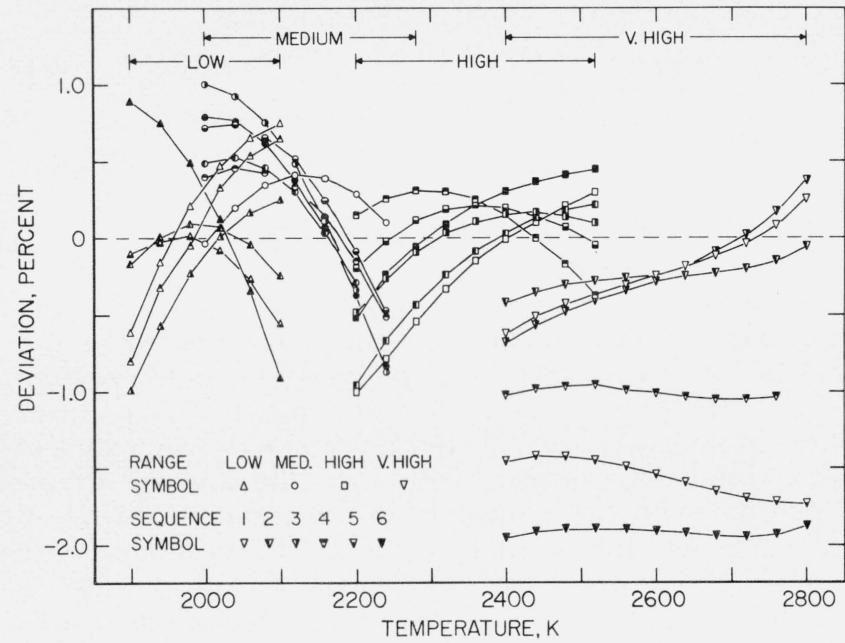

FIGURE 9. Deviation of heat capacity results on molybdenum (first series) from equation (20).

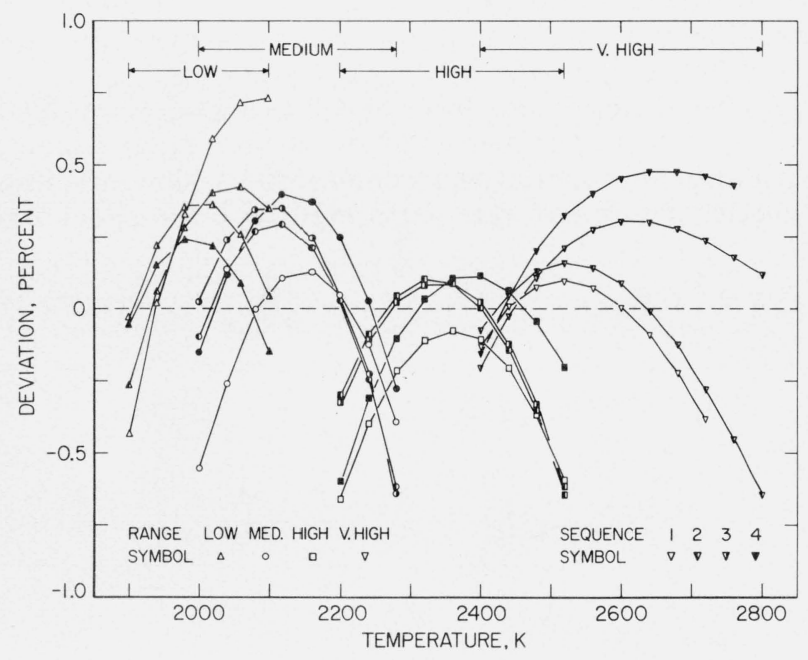

FIGURE 10. Deviation of heat capacity results on molybdenum (second series) from equation (22).

in an argon environment. Comparison of the results (vacuum versus argon environment) yielded an average difference of $0.11 \mathrm{~J} \mathrm{~mol}^{-1} \mathrm{~K}^{-1}(0.31$ percent $)$ in heat capacity, which is approximately equal to the standard deviation of the measurements.

A limited number of experiments was conducted (in vacuum) on another molybdenum specimen, designated as Mo-2. A quadratic fit of the results of three experiments in the medium temperature range yielded a standard deviation of $0.03 \mathrm{~J} \mathrm{~mol}^{-1} \mathrm{~K}^{-1}$ (0.08 percent) in heat capacity. Comparison of the results on Mo-2 with those on Mo-1 (first series) showed an average difference of $0.04 \mathrm{~J} \mathrm{~mol}^{-1} \mathrm{~K}^{-1}(0.12$ percent). The smoothed heat capacity results on Mo-1 and Mo-2 are presented graphically in figure 11. In the computations of heat capacity the atomic weight of molybdenum was taken as 95.94 [13].

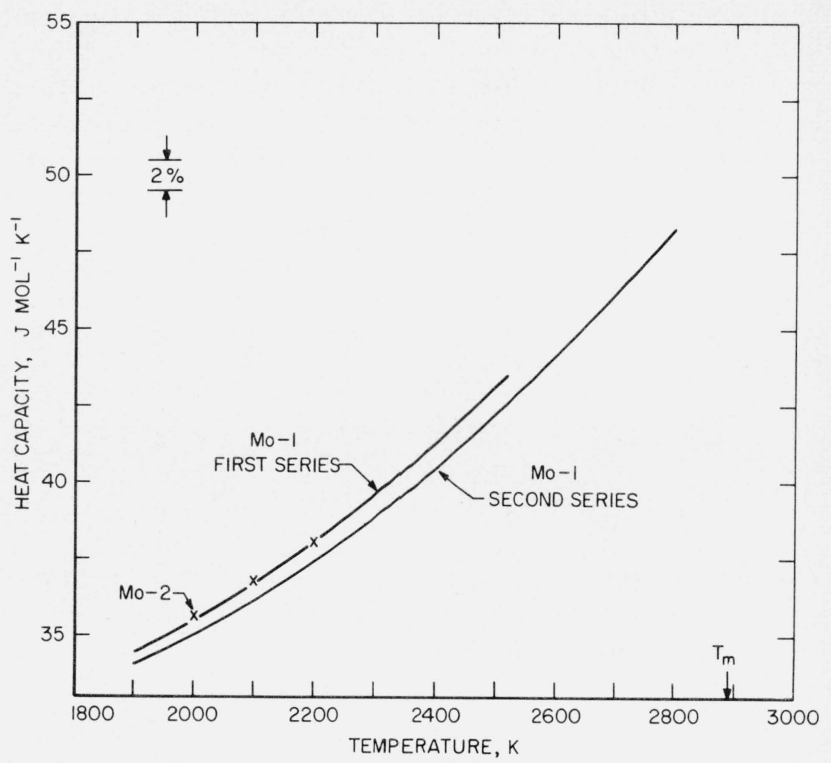

FIGURE 11. Heat capacity results on molybdenum (smooth) for first and second series.

\section{d. Electrical Resistivity}

The experiments which contributed to the determination of electrical resistivity of Mo-1 and Mo-2 were identical with those for heat capacity.

A quadratic function for electrical resistivity for each temperature range and also for each heating series was obtained by least squares approximation of results from individual experiments. As in the heat capacity case, the results of tests in the very high range in the first series showed a systematic drift with time. Because of this, fits involving data of the very high range gave high standard deviations. Since this range was the only exception, the results in the very high range were not considered in the overall fits for the first series. The following equations were obtained:

First series $(1900-2520 \mathrm{~K})$

$\rho=-11.39+3.219 \times 10^{-2} \mathrm{~T}-3.172 \times 10^{-8} T^{2}$

Second series (1900-2800 K) - fast

$\rho=-12.04+3.320 \times 10^{-2} T-4.667 \times 10^{-7} T^{2}$

Second 'series $(1900-2800 \mathrm{~K})-$ slow

$\rho=-13.34+3.445 \times 10^{-2} T-7.417 \times 10^{-7} T^{2}$

where $T$ is in $K$, and $\rho$ is in $10^{-8} \Omega \mathrm{m}$.

Standard deviations (individual point) of the above functions are 0.09 percent for eq (23), 0.07 percent for eq (24), and 0.08 percent for eq (25). The differences between the results of "slow" and "fast" experiments in the second series are given in table 2 . For reasons explained in the previous section, the results of "slow" experiments were considered as the basis of comparison with the results of the first series. Differences between the results of first and second heating series are tabulated in table 3. Deviations of individual results 
from the smooth functions for first and second (slow) heating are presented in figures 12 and 13 , respectively. The experimental results (individual points) on electrical resistivity of molybdenum for the first and second (slow) series are given in the appendix (tables A-1 and A-2).

Comparison of the results (vacuum versus argon environment) yielded an average difference of $0.03 \times 10^{-8} \Omega \mathrm{m}$ (0.06 percent) in electrical resistivity, which is approximately equal to the standard deviation of the measurements.

Quadratic fit of the results for Mo-2 in the medium temperature range gave a standard deviation of $0.02 \times 10^{-8} \Omega \mathrm{m}(0.03$ percent $)$ in electrical resistivity. Comparison of the results for Mo-2 with those for Mo-1 (first series) showed an average difference of $0.31 \times 10^{-8} \Omega \mathrm{m}(0.54$ percent $)$. The smoothed electrical resistivity results on Mo-1 and Mo-2 are presented graphically in figure 14. Results on electrical resistivity at $293 \mathrm{~K}$ are given in section 4.4 .

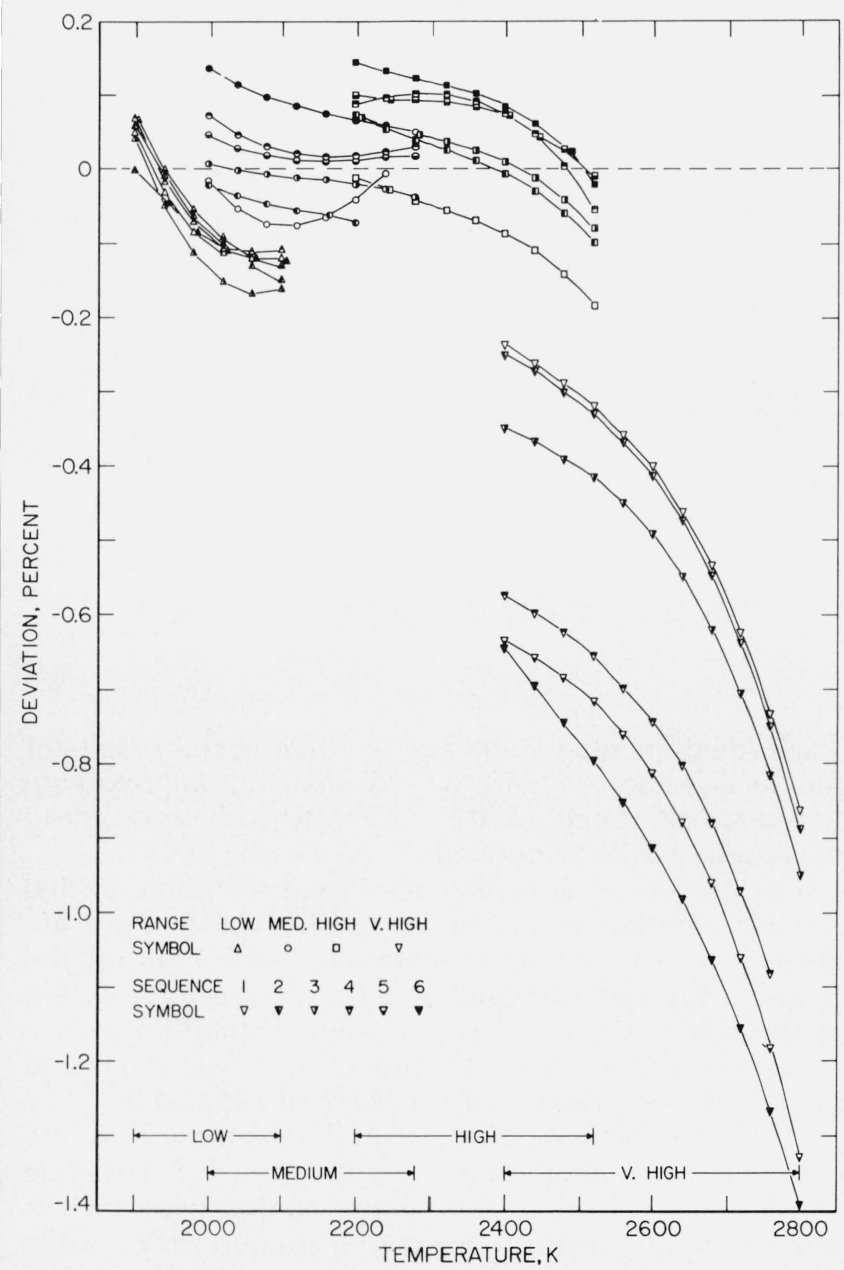

FIGURE 12. Deviation of electrical resistivity results on molybdenum (first series) from equation (23).

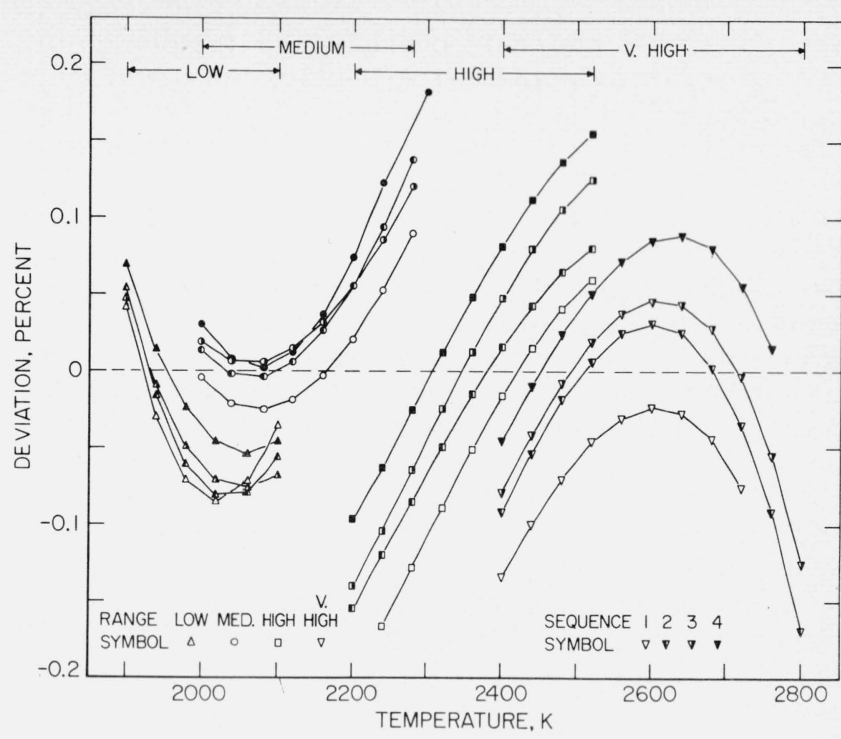

FIGURE 13. Deviation of electrical resistivity results on molybdenum (second series) from equation (25).

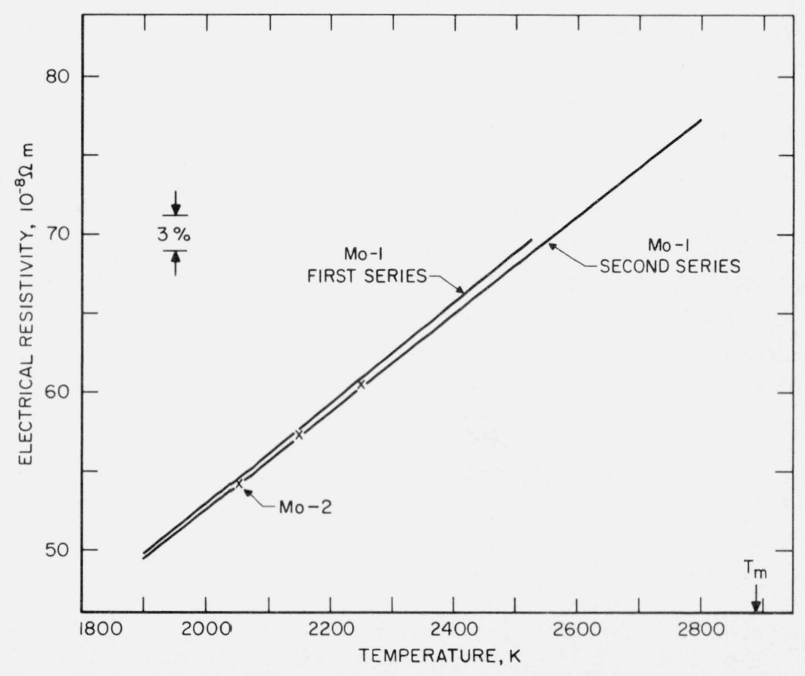

FIGURE 14. Electrical resistivity results on molybdenum (smooth) for first and second series.

\section{Interpretation of Results}

Measurements on all three properties (heat capacity, electrical resistivity, hemispherical total emittance) indicate a difference in the results between the first and second heating series. This difference is approximately one order of magnitude greater than the precision of the measurements. This may be attributed to a change in the physical and chemical state of the specimen which might have taken place during its exposure to high temperatures (above $2500 \mathrm{~K}$, in the very high range) in the first heating series. Since the results on all three properties in the second series are lower than those in the first series, and since no further changes are observed in the very high range of the 
second series, one may consider the results of the second series to be more representative of equilibrium conditions. This is substantiated by: (1) decrease in electrical resistivity (measured under steady-state conditions at $293 \mathrm{~K}$ ), (2) increase in residual electrical resistivity ratio; both between the beginning of first series and the end of second series. An indication of the change in the state of the specimen may be seen by observing the results of weight and resistance measurements that were made before each set of experiments in a given range. These are presented in figure 15. A sudden change in the trend of weight vs. resistance of the specimen is observed which corresponds to the period between the beginning and the end of the set of experiments in the very high range of the first heating series.

All measurements were based on the 1948 International Practical Temperature Scale (IPTS 1948) [64]. This scale was used throughout all the computations as well as in the results expressed by equations given in the previous section. This offered computational convenience and also facilitated the comparison of present results with those in the literature. The final results are corrected to IPTS 1968 [29] by applying proper transformations to both temperature and heat capacity [16].

The results (second series) for heat capacity and electrical resistivity are given in tables 4 and 5 , respectively, both in IPTS 1948 and 1968 scales. Results for electrical resistivity are expressed: (1) in terms of ambient temperature (298 K) dimensions, (2) in terms of corrected high temperature dimensions. High temperature dimensions were obtained by utilizing the following equation for the thermal expansion of molybdenum.

$\frac{l_{T}-l_{298}}{l_{298}}=-6.33 \times 10^{-2}+2.94 \times 10^{-4} T+1.57$

$$
\times 10^{-7} T^{2} .
$$

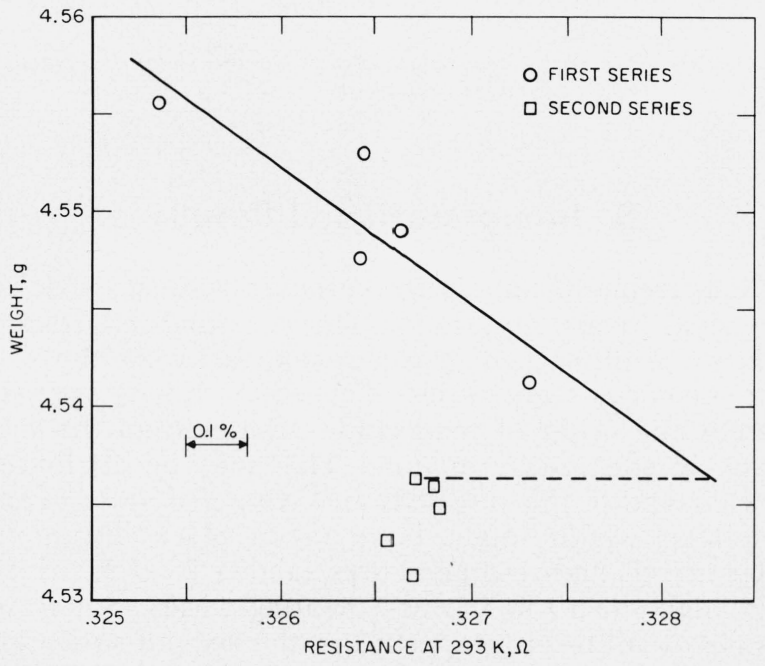

FigURE 15. Weight of molybdenum specimen as a function of resistance at $293 \mathrm{~K}$.
TABLE 4. Heat capacity of molybdenum (second series) corresponding to IPTS 1948 and IPTS 1968

\begin{tabular}{|c|c|c|}
\hline \multirow{2}{*}{$\underset{\mathbf{K}}{\text { Temperature }}$} & \multicolumn{2}{|c|}{$\begin{array}{c}c_{p} \\
\mathrm{~J} \mathrm{~mol}^{-1} \mathrm{~K}^{-1}\end{array}$} \\
\hline & 1948 & 1968 \\
\hline 1900 & 34.06 & 33.97 \\
\hline 2000 & 35.05 & 34.95 \\
\hline 2100 & 36.18 & 36.07 \\
\hline 2200 & 37.47 & 37.35 \\
\hline 2300 & 38.90 & 38.77 \\
\hline 2400 & 40.49 & 40.34 \\
\hline 2500 & 42.22 & 42.06 \\
\hline 2600 & 44.11 & 43.92 \\
\hline 2700 & 46.14 & 45.94 \\
\hline 2800 & 48.33 & 48.10 \\
\hline
\end{tabular}

TABLE 5. Electrical resistivity of molybdenum (second series) corresponding to IPTS 1948 and IPTS 1968

\begin{tabular}{|c|c|c|c|c|}
\hline \multirow{2}{*}{$\begin{array}{c}\text { Tempera- } \\
\text { ture } \\
\mathrm{K}\end{array}$} & \multicolumn{2}{|c|}{$\begin{array}{l}\rho(\mathrm{amb} .)^{\mathrm{a}} \\
10^{-8} \Omega \mathrm{m}\end{array}$} & \multicolumn{2}{|c|}{$\begin{array}{c}\rho \text { (corr. }^{\mathrm{b}}{ }^{\mathrm{b}} \\
10^{-8} \Omega \mathrm{m}\end{array}$} \\
\hline & 1948 & 1968 & 1948 & 1968 \\
\hline 1900 & 49.44 & 49.37 & 49.96 & 49.89 \\
\hline 2000 & 52.59 & 52.52 & 53.20 & 53.12 \\
\hline 2100 & 55.73 & 55.66 & 56.43 & 56.34 \\
\hline 2200 & 58.86 & 58.78 & 59.65 & 59.56 \\
\hline 2300 & 61.97 & 61.88 & 62.87 & 62.77 \\
\hline 2400 & 65.07 & 64.97 & 66.07 & 65.97 \\
\hline 2500 & 68.15 & 68.05 & 69.28 & 69.17 \\
\hline 2600 & 71.22 & 71.11 & 72.47 & 72.35 \\
\hline 2700 & 74.27 & 74.15 & 75.66 & 75.53 \\
\hline 2800 & 77.31 & 77.19 & 78.84 & 78.71 \\
\hline
\end{tabular}

a Based on ambient temperature ( $298 \mathrm{~K})$ dimensions.

${ }^{\mathrm{b}}$ Corrected for dimensions at the specimen temperature.

This equation represents the average of the results of four investigators $[3,18,55,73]$ over the approximate temperature range 1500 to $2800 \mathrm{~K}$ with a standard deviation of 0.04 (3 percent).

The final results on hemispherical total and normal spectral emittances are presented in table 6 . They are given in IPTS 1948 only, since any correction for the temperature scale is much smaller than the resolution of the reported values. Hemispherical total emittance is given both for ambient temperature dimensions and for dimensions corrected for thermal expansion.

Heat capacity results at high temperatures are considerably higher than the Dulong and Petit value of $3 R\left(24.943 \mathrm{~J} \mathrm{~mol}^{-1} \mathrm{~K}^{-1}\right)$. Some of this departure is due to the fact that the measured property is $c_{p}$ while the theory is for $c_{v}$. There is also an additional term which arises from the electronic contribution to heat capacity. 
TABLE 6. Hemispherical total and normal spectral (at $\lambda=650 \mathrm{~nm}$ ) emittances of molybdenum, (second series)

\begin{tabular}{|c|c|c|c|}
\hline \multirow{2}{*}{$\begin{array}{c}\text { Temperature } \\
\text { K }\end{array}$} & \multicolumn{2}{|c|}{$\epsilon$} & \multirow{2}{*}{$\epsilon_{N, \lambda}$} \\
\hline & $(\text { amb. })^{\prime \prime}$ & $(\text { corr. })^{b}$ & \\
\hline 1900 & 0.255 & 0.250 & 0.332 \\
\hline 2000 & .262 & .256 & .331 \\
\hline 2100 & .269 & .263 & .329 \\
\hline 2200 & .276 & .269 & .328 \\
\hline 2300 & .283 & .275 & .327 \\
\hline 2400 & .290 & .281 & .326 \\
\hline 2500 & .298 & .288 & .325 \\
\hline 2600 & .305 & .294 & .324 \\
\hline 2700 & .312 & .300 & .322 \\
\hline 2800 & .319 & .307 & .321 \\
\hline
\end{tabular}

"Based on ambient temperature $(298 \mathrm{~K})$ dimensions.

Corrected for dimensions at the specimen temperature.

Based on thermodynamic principles, the difference between $c_{p}$ and $c_{v}$ is expressed by

$$
c_{p}-c_{v}=\frac{T V \alpha_{v}^{2}}{\beta}
$$

where $V$ is volume, $\alpha_{v}$ coefficient of volume thermal expansion, and $\beta$ is compressibility. Considering the Gruneisen relation

$$
G=\frac{3 V \alpha_{l}}{\beta c_{v}}
$$

where $\alpha_{l}$ is coefficient of linear thermal expansion, and assuming that $G$ is temperature independent, eq (27) becomes

$$
\frac{c_{p}}{c_{v}}=1+3 G \alpha_{l} T
$$

Electronic heat capacity may be expressed by

$$
c_{e}=\gamma T
$$

where $\gamma$ is the coefficient of electronic heat capacity.

It may be seen that, to a first approximation, relations representing $c_{p}-c_{v}$ and $c_{e}$ are linear in temperature. This implies that above the Debye temperature, $\theta$, the measured heat capacity departs from $3 R$ approximately linearly with temperature. In the case of molybdenum, this is found to be true up to approximately $1000 \mathrm{~K}$. Above this temperature present results as well as those in literature are found to increase more rapidly than allowed by a linear function.

The linear term was evaluated with the aid of the recommended values given in JANAF [31] in the temperature interval 200 to $1000 \mathrm{~K}$. Then from the results of the present investigation, a fourth-degree temperature term was added. The relation for heat capacity resulting from this approach (in IPTS 1948) is

$c_{p}=24.943-\frac{1.70 \times 10^{5}}{T^{2}}+3.27 \times 10^{-3} T+2.315 \times 10^{-13} T^{4}$ where the $T^{-2}$ term is the first term in the expansion of the Debye function needed to correlate approximately the temperature region around $\theta$. The average departure of results computed by eq (31) from the quadratic relation representing the present results, eq (22), in the temperature range 1900 to $2800 \mathrm{~K}$ is $0.068 \mathrm{~J} \mathrm{~mol}^{-1} \mathrm{~K}^{-1}(0.17$ percent $)$. This departure is less than the standard deviation of the present measurements. Equation (31) is presented graphically in figure 16.

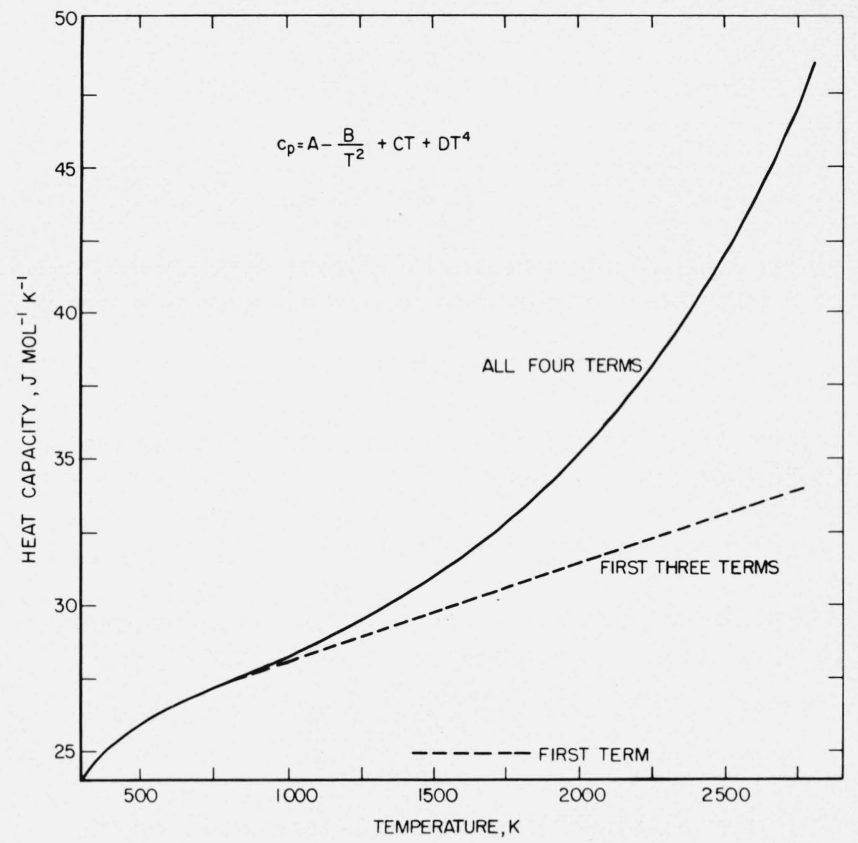

FIGURE 16. Heat capacity of molybdenum according to equation (31).

The $T^{-2}$ term corresponds to a Debye $\theta$ of $370 \mathrm{~K}$ for molybdenum. This value is somewhat lower than those reported in the literature; $\theta=445 \mathrm{~K}$ according to Horowitz [27], $\theta=440 \mathrm{~K}$ according to JANAF [31], and $\theta=459 \mathrm{~K}$ according to Gshneidner [23]. Such a deviation may be expected since in the above analysis only data above $200 \mathrm{~K}$ were considered while other determinations were based on more elaborate treatment of lower temperature data. Argent and Milne [4] reported that $\theta$ for molybdenum based on low temperature data is $445 \mathrm{~K}$, while based on high temperature data it becomes $380 \mathrm{~K}$. The latter value is very close to that of the present study.

The reported values for the coefficient of the electronic heat capacity for molybdenum are: $\gamma=$ $2.13 \times 10^{-3} \mathrm{~J} \mathrm{~mol}^{-1} \mathrm{~K}^{-2}$ according to Horowitz [27], and $\gamma=1.97 \times 10^{-3} \mathrm{~J} \mathrm{~mol}^{-1} \mathrm{~K}^{-2}$ from JANAF [31]. If one assumes a value of 1.5 for the Gruneisen constant and one considers the values of $6.1 \times 10^{-6} \mathrm{~K}^{-1}$ for the coefficient of linear thermal expansion at $1000 \mathrm{~K}$ given by Kirby [34], the coefficient for the $c_{p}-c_{v}$ term becomes $0.68 \times 10^{-3} \mathrm{~J} \mathrm{~mol}^{-1} \mathrm{~K}^{-2}$. If one considers the higher of the two $\gamma$ values and adds to it the coefficient of $c_{p}-c_{v}$ term, the sum becomes $2.81 \times 10^{-3} \mathrm{~J} \mathrm{~mol}^{-1} \mathrm{~K}^{-2}$, which is somewhat lower than the coefficient of the linear term $\left(3.27 \times 10^{-3}\right)$ in eq (31). The result of the 
sum of the first three terms on the right-hand side of eq (31) is represented by the dashed curve in figure 16 . It may be seen that this curve is much lower than that representing measured heat capacity at high temperatures.

No satisfactory explanation has been found as to the nature of the increase of heat capacity above the combined value of $3 R$ and the linear term at high temperatures. Although the mechanisms of vacancy generation become important at high temperatures, it is not possible to attribute the high values entirely to vacancies.

Vacancy concentration $n$, in fractional form, may be expressed by

$$
n=A e^{-\frac{E_{f}}{k T}}
$$

where $E_{f}$ is vacancy formation energy. Energy per mole of a substance required to form vacancies is given by

$$
U=n N_{A} E_{f}
$$

where $N_{A}$ is Avogadro's number. Substituting eq (32) in eq (33), one obtains

$$
U=N_{A} A E_{f} e^{-\frac{E_{f}}{k T}} .
$$

Then, the expression for the contribution of vacancies to heat capacity becomes

$$
c_{\mathrm{vac}}=\frac{N_{A} A E_{f}^{2}}{k T^{2}} e^{-\frac{E_{f}}{k T}}
$$

If one assumes that vacancy formation energy is approximately proportional to the melting point and considers the value $0.97 \mathrm{eV}$ given by DeSorbo [14] for gold, one obtains $2.10 \mathrm{eV}$ for the vacancy formation energy of molybdenum. This is in reasonable agreement with the values $2.4 \mathrm{eV}, 2.24 \mathrm{eV}$, and $1.86 \mathrm{eV}$ given by Meakin et al. [45], Kraftmacher [38] and Kirillin et al. [36], respectively. If one considers the vacancy formation energy of $3.30 \mathrm{eV}$ for tungsten reported by Schultz [59], the estimated value for the vacancy formation energy for molybdenum becomes $2.59 \mathrm{eV}$. There are no accurate measurements on molybdenum related to vacancy concentration at high temperatures. Dilatometric measurements made by Simmons and Balluffi [61, 62] on gold and copper by combined direct optical and x-ray techniques indicate vacancy concentrations of approximately 0.07 and 0.09 percent at their respective melting points. The results of quenching experiments on tungsten reported by Schultz [59] give a vacancy concentration of 0.011 percent at its melting point. Quenching experiments on molybdenum described by Meakin et al. [45] indicate a vacancy concentration of 0.005 percent at its melting point.

The contribution of vacancy formation to the heat capacity of molybdenum is estimated with the assumption of a somewhat high vacancy concentration of 0.1 percent at the melting point $(2889 \mathrm{~K})$ and a vacancy formation energy of $2.1 \mathrm{eV}$. The results are presented in table 7 together with the quartic term in eq (31)
TABLE 7. Estimated vacancy contribution to heat capacity of molybdenum and $\mathrm{DT}^{4}$ in eq $(31)$

\begin{tabular}{c|c|c}
\hline \hline$T$ & $c_{\text {vac }}$ & $\mathrm{DT}^{4}$ \\
\hline $\mathrm{K}$ & $\mathrm{J} \mathrm{mol}^{-1} \mathrm{~K}^{-1}$ & $\mathrm{~J} \mathrm{~mol}^{-1} \mathrm{~K}^{-1}$ \\
\hline & & \\
2000 & 0.03 & 3.70 \\
2200 & .07 & 5.42 \\
2400 & .15 & 7.68 \\
2600 & .29 & 10.58 \\
2800 & .48 & 14.23 \\
\hline
\end{tabular}

which represents the magnitude to which the measured heat capacity departs from the sum of $3 R$ and the linear term at high temperatures. Vacancy contribution is evidently small, less than $0.5 \mathrm{~J} \mathrm{~mol}^{-1} \mathrm{~K}^{-1}$ (upper limit) at $2800 \mathrm{~K}$, and does not account for high heat capacity values. The fact that electrical resistivity does not show any sharp increase at high temperatures is also an indication that the effect of vacancies is small. A recent discussion on thermodynamic properties of solids containing vacancies is given by Holder and Granato [26]. Energy associated with grain growth during heating is also negligible compared to the total energy absorbed by the specimen [44]. A possible contribution of higher order terms in the electronic heat capacity may partially account for high values of heat capacity at high temperatures.

If the entire deviation of measured heat capacity from the sum of $3 R$ and the linear term at high temperatures is represented by an expression similar to eq (35), one could obtain, after rearrangement

$$
\ln \left(T^{2} \Delta c_{p}\right)=\ln B-\frac{M}{T}
$$

This equation indicates that a plot of the left side versus $1 / T$ should yield a straight line with slope equal to $-M$. From the data on molybdenum in the range 1900 to $2800 \mathrm{~K}$, a straight line with a standard deviation of 0.3 percent was obtained. However, the parameters obtained through this fit do not seem to have any physical significance. As a crude analogy to vacancy concentration, the computations yiclded a value of $1.21 \mathrm{eV}$ for energy and 7.5 percent for concentration at the melting point. Both of these values seem to be unrealistic for molybdenum.

Unlike heat capacity and electrical resistivity, thermal radiation properties are very sensitive to surface conditions (mechanical, chemical, etc.). Therefore, it is difficult to correlate measured quantities in terms of the fundamental properties of the substance. In this investigation the main motivation in the measurement of both hemispherical total and normal spectral emittances was to apply corrections to heat capacity and temperature, respectively. However, as seen in the next section, the results are in good agreement with those in the literature. 


\section{Comparison With Results in Literature}

\subsection{Heat Capacity}

Above approximately $1000 \mathrm{~K}$, heat capacity reported in the literature was measured both by drop and pulse calorimetry. The quantity measured in drop calorimetry is enthalpy. Therefore, in order to obtain heat capacity, one has to fit enthalpy data to a smooth function and differentiate that function with respect to temperature. In pulse calorimetry, heat capacity is obtained directly through the measurement of the quantity $d T / d t$, the rate of change of temperature with time.

The results reported in the literature for the heat capacity of molybdenum are presented in figure 17. A comparison of selected literature results with those of the present study is given in table 8. All values are based on IPTS 1948. Estimates of errors in papers cited lead to an estimate of inaccuracy in previously reported heat capacity of approximately 4 to 7 percent in the temperature range considered. The agreement is within the combined estimated errors in all cases. However, if equal weight is given to literature values, the present results from the second series are systematically low by about 1.5 percent. Although the results from the first series are in good agreement with the average of previous measurements, it is believed that they are less accurate than those from the second series.

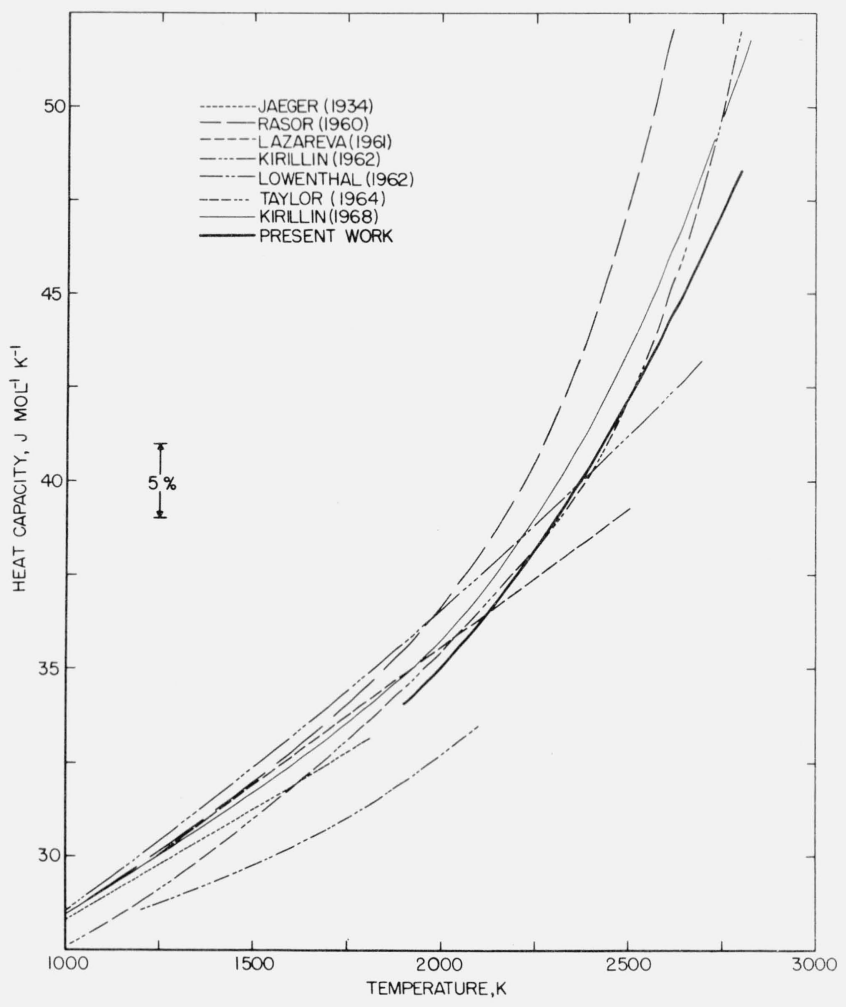

FIGURE 17. Heat capacity of molybdenum reported in the literature.

TABLE 8. Heat capacity difference (previous literature values minus present work, second series, values) in percent

\begin{tabular}{|c|c|c|c|c|c|c|c|c|}
\hline \multirow{2}{*}{ Investigator } & \multirow{2}{*}{ Ref. } & \multirow{2}{*}{ Year } & \multirow{2}{*}{ Method } & \multicolumn{5}{|c|}{ Temperature, $\mathrm{K}$} \\
\hline & & & & 2000 & 2200 & 2400 & 2600 & 2800 \\
\hline 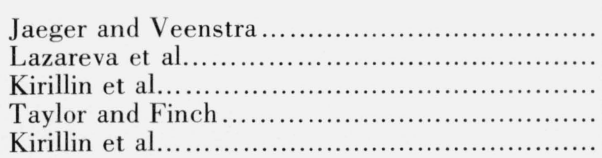 & $\begin{array}{l}30 \\
42 \\
35 \\
65 \\
36\end{array}$ & $\begin{array}{l}1934 \\
1961 \\
1962 \\
1964 \\
1968\end{array}$ & $\begin{array}{l}\text { drop } \\
\text { drop } \\
\text { drop } \\
\text { pulse } \\
\text { drop }\end{array}$ & $\begin{array}{l}\mathrm{a} \\
\quad+2.1 \\
+1.5 \\
+4.3 \\
+1.0 \\
+2.1\end{array}$ & $\begin{array}{l}-1.2 \\
+2.4 \\
+0.4 \\
+2.2\end{array}$ & $\begin{array}{l}-4.9 \\
-0.6 \\
-0.8 \\
+2.6\end{array}$ & $\begin{array}{l}-4.3 \\
+1.6 \\
+3.8\end{array}$ & $\begin{array}{l}+7.6 \\
+5.7\end{array}$ \\
\hline
\end{tabular}

\footnotetext{
${ }^{\text {a }}$ Extrapolated from $1873 \mathrm{~K}$.
}

\subsection{Electrical Resistivity}

The electrical resistivity of molybdenum reported in the literature was measured by steady-state techniques. Since transport properties are sensitive to the history of the specimen, one would expect to see differences in the results of various investigators. The literature results for the electrical resistivity of molybdenum are presented in figure 18. A comparison of selected literature results with those of the present study is given in table 9. All values are based on IPTS 1948. Estimates of errors in papers cited lead to an estimate of inaccuracy in previously reported electrical resistivity of approximately 1 to 2 percent in temperature range considered. Measurements of the electrical
TABLE 9. Electrical resistivity difference (previous literature values minus present work, second series, values) in percent

\begin{tabular}{|c|c|c|c|c|c|c|c|}
\hline \multirow{2}{*}{ Investigator } & \multirow{2}{*}{ Ref. } & \multirow{2}{*}{ Year } & \multicolumn{5}{|c|}{ Temperature, $\mathrm{K}$} \\
\hline & & & 2000 & 2200 & 2400 & 2600 & 2800 \\
\hline $\begin{array}{l}\text { Worthing.... } \\
\text { Osborn....... }\end{array}$ & $\begin{array}{l}73 \\
48 \\
66\end{array}$ & $\begin{array}{l}1926 \\
1941\end{array}$ & $\begin{array}{l}+1.1 \\
+0.1 \\
+10\end{array}$ & +0.9 & +0.9 & +1.2 & +1.6 \\
\hline Taylor... & 66 & 1964 (p.c.) & +1.0 & +0.2 & -0.3 & -0.5 & -0.5 \\
\hline
\end{tabular}

resistivity of molybdenum corresponding to $293 \mathrm{~K}$, as well as values reported in the literature, are given in table 10. 


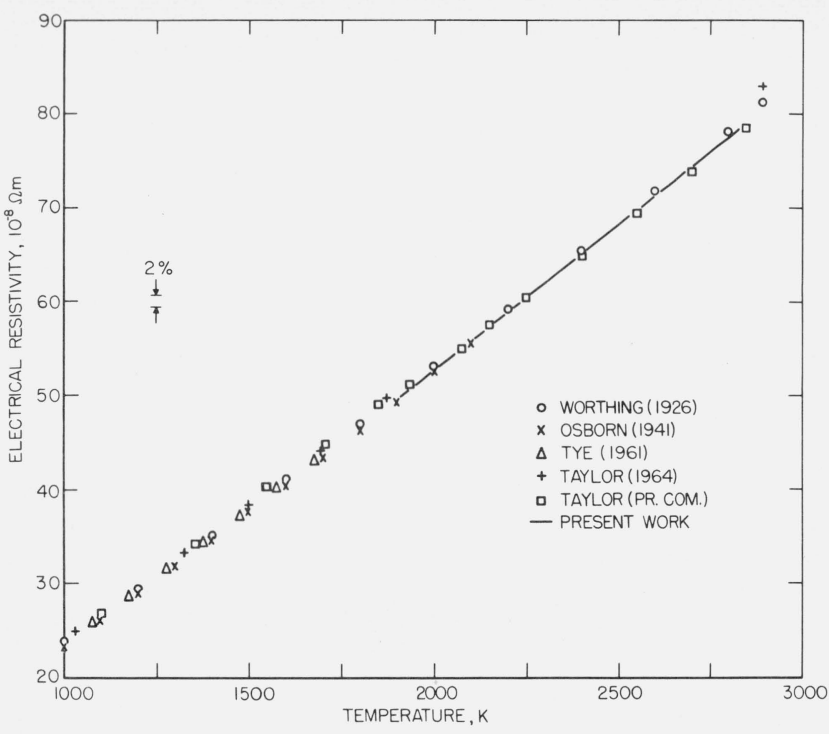

FIGURE 18. Electrical resistivity of molybdenum reported in the literature.

TABLE 10. Electrical resistivity of molybdenum at $293 \mathrm{~K}$ (literature)

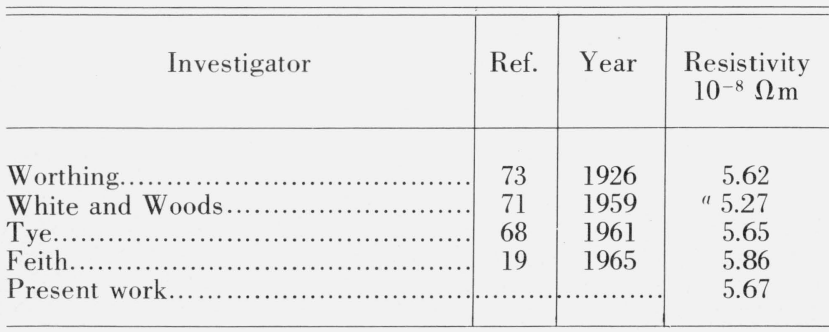

"Ideal resistivity.

\subsection{Hemispherical Total and Normal Spectral Emittances}

Because of the strong dependence of emittance on surface conditions, large deviations are to be expected between the results of various investigators.

Results for hemispherical total and normal spectral emittances of molybdenum reported in the literature are presented in figures 19 and 20, respectively.

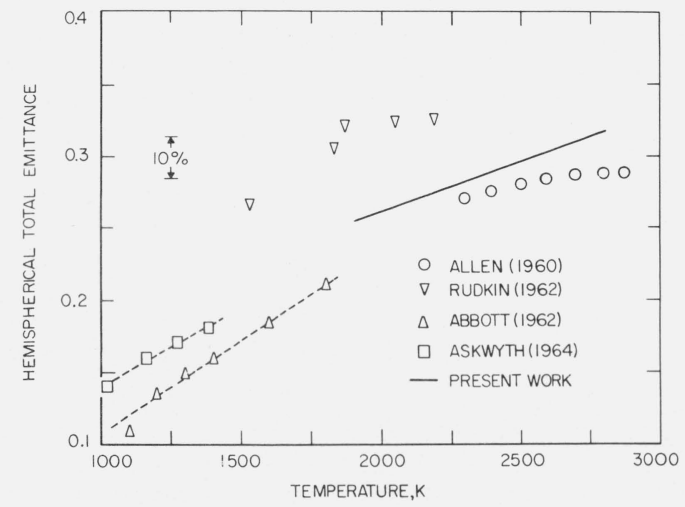

FIGURE 19. Hemispherical total emittance of molybdenum reported in the literature.

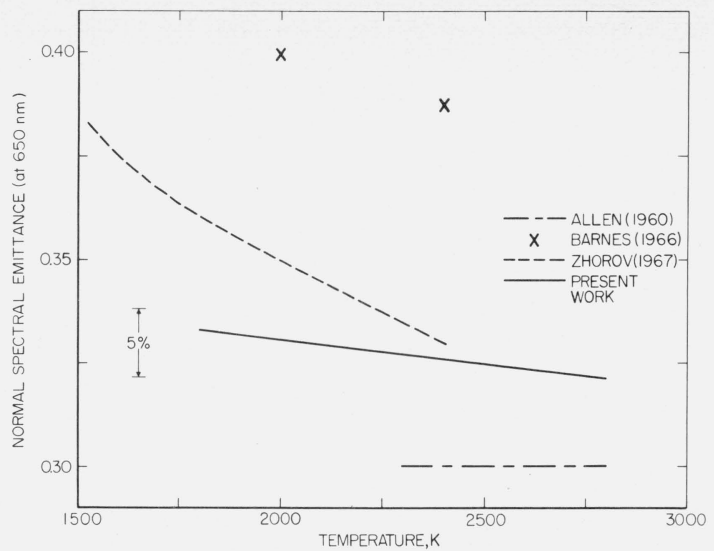

FigURE 20. Normal spectral emittance of molybdenum at $\lambda=650$ $n m$ reported in the literature.

\section{Estimate of Errors}

Uncertainty in properties depends upon: (1) errors in directly measured quantities, and (2) departure from assumed operational conditions. These are discussed in the following sections.

In this paper the term "imprecision", unless otherwise stated, refers to the standard deviation of the individual measurement; computed from the differences of single data points from a polynomial function fitted by the method of least squares. The term "inaccuracy", unless otherwise stated, refers to the estimated maximum total error (random and systematic) approximately equivalent to two standard deviations.

\subsection{Errors in Directly Measured Quantities}

Estimated total error (which includes random as well as systematic errors) in directly measured quantities such as temperature, voltage, current, dimensions, weight, etc., is obtained from auxiliary tests, analyses of experimental results or computations of several minor sources of error. The details are given below.

\section{a. Errors in Temperature Measurements}

Total error in temperature measurements results from several contributions. Their estimates are summarized in the following paragraphs.

Standard Lamp. The National Bureau of Standards report of calibration for the tungsten filament standard lamp states "The maximum uncertainties of the values reported correspond to about \pm 1 degree at $1500{ }^{\circ} \mathrm{C}$ and increase to about \pm 2.5 degrees at $2200{ }^{\circ} \mathrm{C}$ ". In the measurements above $2500 \mathrm{~K}$ an attenuator was used in the unknown channel. The uncertainty due to the attenuator's calibration brings the total uncertainty at $2800 \mathrm{~K}$ to $3.5 \mathrm{~K}$.

Stability of Standard Lamp. Calibrations of the standard lamp before and after the entire set of experiments show a change of approximately $0.9 \mathrm{~K}$ at $2000 \mathrm{~K}$ and $1.4 \mathrm{~K}$ at $2500 \mathrm{~K}$. In the computations of 
the properties an average of the initial and final calibrations was used which reduced the temperature inaccuracy due to lamp instability to $0.5 \mathrm{~K}$ at $2000 \mathrm{~K}$ and $1 \mathrm{~K}$ at $2800 \mathrm{~K}$.

Radiation Source Alinement. Since the pyrometer had to be moved between a calibration and a pulse experiment and again for a calibration during each set of experiments in a given temperature range, an additional uncertainty in the calibration of the pyrometer develops as a result of the uncertainties in the visual alinement of the lamps. Based on an analysis of experimental results on approximately 20 tests with steady-state radiation sources, it is estimated that the error arising from this uncertainty is approximately $1 \mathrm{~K}$ at $2000 \mathrm{~K}$ and $2 \mathrm{~K}$ at $2800 \mathrm{~K}$.

Pyrometer Reproducibility. Based on calibration results, the short time reproducibility of the pyrometer (between two calibrations in one day) is estimated to be approximately $1 \mathrm{~K}$ at $2000 \mathrm{~K}$ and $2 \mathrm{~K}$ at $2800 \mathrm{~K}$. This includes changes in the optical attenuations in the pyrometer that result from the collection of dust, etc.

Scattered Light Correction. Although a correction was made to temperature to allow for the scattering effect in the optics of the pyrometer, an uncertainty still exists as to the actual magnitude of this correction. The uncertainty in the scattering factor $\mathrm{S}$ given by eq (14) is obtained by considering the uncertainties in scattering ratio and normal spectral emittance. The results indicate an uncertainty of 0.5 percent in radiance which corresponds to approximately $0.4 \mathrm{~K}$ at $2000 \mathrm{~K}$ and $1 \mathrm{~K}$ at $2800 \mathrm{~K}$.

Blackbody Quality (Geometrical). The computed blackbody quality $(0.995)$, which was based on geometrical considerations only, is estimated to have a maximum uncertainty of 0.5 percent (in radiance) which corresponds to approximately $1 \mathrm{~K}$ at $2000 \mathrm{~K}$ and $2 \mathrm{~K}$ at $2800 \mathrm{~K}$.

Specimen Temperature Nonuniformity. Heat transfer from specimen to clamps causes the establishment of temperature gradients in the specimen. However, since the "effective" portion of the specimen (between potential probes) is $12.7 \mathrm{~mm}$ away from the clamps, the sharp temperature gradients near them do not affect the measurements. The magnitude of the axial temperature gradient in the "effective" specimen is estimated by solving the transient heat conduction equation assuming constant properties [11]. Computations indicate that the average temperature in the "effective" specimen in the "slow" experiments due to axial heat conduction is approximately $1 \mathrm{~K}$ below midpoint value at $2000 \mathrm{~K}$ and $2 \mathrm{~K}$ below at $2800 \mathrm{~K}$, and the difference, of course, is less in the "fast" experiments.

Radial temperature difference across the thin wall specimen is calculated for the "slow" experiments to be less than $0.1 \mathrm{~K}$ at $2000 \mathrm{~K}$ and $0.5 \mathrm{~K}$ at $2800 \mathrm{~K}$. No corrections were made for the small axial and radial temperature gradients. Effect of the sighting hole on temperature distribution in the specimen is considered negligible for good conductors [28].

From potentiometric measurements of the resistance of the specimen along its length at room temperature, random variations in the thickness of the tube averaged over lengths of approximately $3 \mathrm{~mm}$ were estimated. Temperature nonuniformity corresponding to the variations in the thickness of the specimen is approximately $2 \mathrm{~K}$ at $2000 \mathrm{~K}$ and $4 \mathrm{~K}$ at $2800 \mathrm{~K}$.

The total temperature inaccuracy resulting from the above items is estimated to be approximately $3 \mathrm{~K}$ at $2000 \mathrm{~K}$ and $4 \mathrm{~K}$ at $2800 \mathrm{~K}$.

Error in Window Attenuation. The interpolations which were made before and after each set of experiments in a given range introduce a small additional error of approximately $0.5 \mathrm{~K}$ at $2000 \mathrm{~K}$ and $1 \mathrm{~K}$ at 2800 $K$. The magnitude of this effect is estimated from the drift of the electrical resistivity results in a given set of experiments.

Magnetic Fields. The effect on the pyrometer of varying electric and magnetic fields associated with the pulse currents was tested and was found to be negligible (less than $0.5 \mathrm{~K}$, the resolution of temperature measurements).

Use of Wien's Law. For the computations of temperature, Wien's instead of Planck's Law was used. The difference in temperature obtained by these two functions for the mean wavelength of $650 \mathrm{~nm}$ is approximately $0.003 \mathrm{~K}$ at $2000 \mathrm{~K}$ and $0.13 \mathrm{~K}$ at $2800 \mathrm{~K}$. Since the same procedure was used for both calibration and pulse experiments, the error introduced as the result of the use of Wien's Law is completely negligible.

Resultant Error in Temperature. From a consideration of various errors and their magnitudes listed above, it may be concluded that the inaccuracy in temperature measurements is approximately $4 \mathrm{~K}$ at $2000 \mathrm{~K}$ and $7 \mathrm{~K}$ at $2800 \mathrm{~K}$. A summary of estimated errors in temperature is given in table 11 .

\section{b. Errors in Electrical Measurements}

Identifiable sources of errors that affect the measurement of electrical quantities, such as voltage and current, are given below.

Skin Effect. Since molybdenum is nonmagnetic and the specimen was of tubular shape and the current was a single trapezoidal pulse of several hundred milli-

TABLE 11. Estimated inaccuracies in temperature measurements

\begin{tabular}{|c|c|c|c|}
\hline & \multirow{2}{*}{ Source } & \multicolumn{2}{|c|}{ Inaccuracy, $\mathrm{K}$} \\
\hline & & at $2000 \mathrm{~K}$ & at $2800 \mathrm{~K}$ \\
\hline 1 & Standard Lamp..... & 1.5 & 3.5 \\
\hline 2 & Instability of Standard Lamp..... & 0.5 & 1 \\
\hline 3 & Radiation Source Alinement....... & 1 & 2 \\
\hline 4 & Pyrometer Reproducibility......... & 1 & 2 \\
\hline 5 & Scattered Light Correction........ & 0.5 & 1 \\
\hline 6 & Blackbody Quality.................. & 1 & 2 \\
\hline 7 & $\begin{array}{l}\text { Specimen Temperature Non- } \\
\text { Uniformity. }\end{array}$ & 3 & 4 \\
\hline 8 & Window Attenuation............... & 0.5 & 1 \\
\hline & $\begin{array}{l}\text { Total Inaccuracy in Tempera- } \\
\text { ture. a }\end{array}$ & 4 & 7 \\
\hline
\end{tabular}

${ }^{\text {a }}$ Root sum square of items 1 to 8 . 
seconds duration, the contribution of skin effect is negligible. Computations indicate that in the present experiments the skin effect (which manifests itself as a change in effective resistance of the conductor) was much less than 0.01 percent.

Inductive Effects. Consideration of self- and mutualinductances [22] of pertinent components indicate that their contribution to the electrical signals is less than $1 \mathrm{mV}$, which is the resolution of the digital data acquisition system. This is due to the fact that the current changes slowly during the period of the measurements.

Thermoelectric Effects. Both experimental checks and computations indicate that the contribution of the thermoelectric effects in the present system is less than $1 \mathrm{mV}$, which is the resolution of the digital data acquisition system.

Errors Due to Calibrations. A precision voltage source $(0.001$ percent stability) and potentiometric method were used for the calibration of the electrical measuring circuits. Moreover, the stability of the components (amplifiers, analog-to-digital converter, etc.) was better than 0.01 percent over the actual period of measurements. This implies that the limiting factor in the electrical calibrations was the resolution of the digital data acquisition system.

Resultant Error in Electrical Measurements. The estimated error in electrical measurements arising from items listed above is only a few parts in $10^{4}$. In order to have a more direct check on the accuracy of electrical measurements, experiments were conducted to determine the value of a test resistance by measuring the current flowing through it and the voltage drop across its terminals under transient conditions and comparing this measurement with its resistance under steady-state conditions as determined by the potentiometric method. The average of the results of nine experiments indicates that resistance measurements by pulse and steady-state techniques are in agreement within 0.02 percent.

Based on the foregoing, the estimated inaccuracies in voltage and current measurements are 0.05 and 0.06 percent, respectively, introducing an inaccuracy of 0.08 percent in power and resistance.

\section{c. Errors in Other Measurements}

Length. The inaccuracy in an individual length measurement is $0.03 \mathrm{~mm}$. When related to the specimen dimensions, it yields an inaccuracy of approximately 0.04 percent. Based on this, the inaccuracy in establishing the length of the "effective" specimen becomes approximately 0.08 percent.

Weight. The inaccuracy in an individual weight measurement is $0.5 \mathrm{mg}$, producing an inaccuracy of less than 0.01 percent for the specimen. However, the uncertainty in determining the weight of the "effective" specimen is greater than this. Based on the combined uncertainties of weight and length measurements, the inaccuracy in the weight of the "effective" specimen is estimated to be not more than 0.1 percent.
Density. The inaccuracy in density measurements is approximately 0.1 percent. This uncertainty enters into the computation of the thickness of the specimen.

Time. The time base of the experiments was a synchronous motor which derived its power from a 400 $\mathrm{Hz}$ regulated power supply. Measurements have indicated that the inaccuracy in time due to frequency instability was less than 0.005 percent.

\subsection{Errors Due to Departure from Assumed Conditions}

\section{a. Errors in Heat Loss Correction}

Since the dynamic experiments were made with the specimen in vacuum, heat loss from the specimen took place by thermal radiation and by axial conduction to the end clamps. In the previous section it was reported that axial temperature gradients in the "effective" specimen were very small; thus heat loss by conduction in the axial direction is negligible. Heat conduction to the voltage probes is also negligible since the cross-sectional area of the knife-edges is small and the conduction path is long. Thus, thermal radiation is the only major source of heat loss. To correct for this, a term representing thermal radiation is included in the relation for heat capacity, eq (2). However, any uncertainty in this term affects heat capacity. Radiation heat loss, which was obtained from data during the cooling period, has an uncertainty of approximately 1 percent. Then, uncertainty in heat capacity is obtained by multiplying the uncertainty in heat loss by thermal radiation by the ratio of radiated power to input power. Results of "slow" experiments indicate that the contribution of this uncertainty to heat capacity is approximately 0.03 percent at $2000 \mathrm{~K}$ and 0.14 percent at $2800 \mathrm{~K}$. This uncertainty, of course, is less in "fast" experiments.

\section{b. Evaporation}

Evaporation at high temperatures introduces effects due to: (1) the heat of vaporization of the material lost, and (2) reduction in the mass of the specimen. Using evaporation data given by Jones et al. [32] and vapor pressures tabulated by JANAF [31], the total weight loss corresponding to present experimental conditions was computed. The resulting total weight loss is $3 \times 10^{-5} \mathrm{mg}$ and $0.35 \mathrm{mg}$ per experiment in dynamic experiments where temperature maxima were at approximately $2000 \mathrm{~K}$ and $2800 \mathrm{~K}$, respectively. The measured weight loss was $0.1 \mathrm{mg}$ and $0.36 \mathrm{mg}$ for approximately the same temperatures. This shows that evaporation accounts for most of the weight loss at high temperatures. The relatively large measured weight loss at lower temperatures which cannot be attributed to evaporation may be due to oxidation and subsequent evaporation of the oxide. At the highest temperature weight loss is less than 0.01 percent of the weight of the effective specimen, thus the effect of evaporation on the results is negligible. The heat loss effect computed was much smaller than radiation loss. It is included in the radiation heat loss correction to the heat capacity and hence does not contribute any additional error to heat capacity, but may introduce a small error in the hemispherical total emittance. 


\section{c. Thermionic Emission}

Considering the values $55 \times 10^{4} \mathrm{~A} \mathrm{~m}^{-2} \mathrm{~K}^{-2}$ for the thermionic emission constant and $4.15 \mathrm{eV}$ for the thermionic work function of molybdenum [17, 63], thermionic emission current is computed to be approximately $7 \times 10^{-5} \mathrm{~A} \mathrm{~mm}^{-2}$ at $2000 \mathrm{~K}$ and $0.15 \mathrm{~A} \mathrm{~mm}^{-2}$ at $2800 \mathrm{~K}$. It may be noted that computed values are for the case where electrons are continuously removed from the surface which requires a collector plate at positive potential. In the present system, the chamber wall is electrically neutral and the only electrical potential gradient that exists is that across the specimen, which is less than $10 \mathrm{~V}$. Thus, in the present experiments thermionic emission is most probably space charge limited, as a result of which its contribution is much less than the values computed above and therefore negligible. Since the positive ion work function for molybdenum is $8.6 \mathrm{eV}$ [74], the contribution of positive ion emission can also be neglected.

\subsection{Statistical Error Analysis of Experimental Results}

Possible sources and estimates of combined systematic and random errors were discussed in the previous sections. In this section, an analysis of heat capacity and electrical resistivity results is presented from the viewpoint of the random errors in the experimental data.

The imprecision in the determination of properties may be calculated both in terms of the imprecision of a set of data in a single experiment and in terms of the imprecision of the results of many experiments.

\section{a. Imprecision of Heat Capacity in a Single Experiment}

The variables which contribute random uncertainty to the heat capacity in a single experiment are: voltage, current, temperature, and heating rate. Each of these variables enters the heat capacity calculation as a function of time. The uncertainty of an individual voltage, current, or temperature has been obtained as a percent standard deviation in the course of the computer calculation of a variable-time equation according to the following equation:

$$
s=\left[\frac{\sum\left(\frac{T_{\mathrm{obs}}-T_{\mathrm{cal}}}{T_{\mathrm{obs}}}\right)^{2}}{n-3}\right]^{1 / 2}
$$

where $n$ is the number of measurements in an experiment. From experimental results the average standard deviation is found to be 0.02 percent for temperature, 0.02 percent for voltage and 0.03 percent for current. The uncertainty of a heating rate has been calculated from the standard deviation of the coefficients of the temperature-time equation differentiated to obtain the heating rate. Although temperature and heating rate are interdependent functions, the variances in heat capacity derived from these two variables are so different in magnitude that they are treated here as independent functions.
The total variance in heat capacity, $s_{c}^{2}$, resulting from uncertainties in the four variables is given by

$$
s_{c}^{2}=s_{c e}^{2}+s_{c i}^{2}+s_{c T}^{2}+s_{c r}^{2}
$$

which may be expressed as

$$
s_{c}^{2}=s_{e}^{2}\left(\frac{\partial c}{\partial e}\right)^{2}+s_{i}^{2}\left(\frac{\partial c}{\partial i}\right)^{2}+s_{T}^{2}\left(\frac{\partial c}{\partial T}\right)^{2}+s_{r}^{2}\left(\frac{\partial c}{\partial r}\right)^{2}
$$

where $s_{c e}^{2}$ is the heat capacity variance contributed by voltage, $s_{c i}^{2}$ by current, $s_{c T}^{2}$ by temperature, $s_{c r}^{2}$ by heating rate; and $s_{e}^{2}, s_{i}^{2}, s_{T}^{2}, s_{r}^{2}$ are the variances of the variables voltage, current, temperature, and heating rate, respectively. The result of computations of above quantities yields an average random uncertainty of 0.55 percent for heat capacity.

\section{b. Imprecision of Heat Capacity from a Series of Experiments}

A large number of experiments was conducted in several temperature ranges. Each experiment consisted of approximately 50 sets of measurements of temperature, voltage, and current, which have standard deviations discussed above. When heat capacity was computed from these quantities and the results of the many experiments were combined to obtain a polynomial function, the resultant standard deviation was 0.32 percent. However, since individual experimental results had been smoothed in the initial data reduction, the 0.32 percent standard deviation does not include all of the random variations that would have been observed without this prior processing. If the sum of the variances for the two processes are taken into consideration, one obtains an estimate of the variance of an individual determination which gives approximately 0.6 percent for this standard deviation of an individual point. This is an indication of the imprecision of the measurement. However, the imprecision of a single determination has relatively little effect on the inaccuracy of the results because (1) imprecision is already much smaller than estimated total error, (2) properties are obtained from several thousand measurements of temperature and electrical quantities.

\section{c. Imprecision of Electrical Resistivity in a Single Experiment}

The variables affecting the imprecision of resistivity based on room-temperature dimensions are voltage and current. The uncertainty in the dimensions of the electrical path represent a systematic error only. Total variance in electrical resistivity, $s_{\rho}^{2}$, resulting from uncertainties in the two variables may be expressed by the following equation.

$$
s_{\rho}^{2}=s_{e}^{2}\left(\frac{\partial \rho}{\partial e}\right)^{2}+s_{i}^{2}\left(\frac{\partial \rho}{\partial i}\right)^{2} .
$$

The result of above computations gives an average imprecision of 0.032 percent for electrical resistivity. 
d. Imprecision of Electrical Resistivity from a Series of Experiments

The function combining all the resistivity experiments shows a standard deviation of 0.076 percent for the second series. As in the case of heat capacity, this represents the variability of different groups of smoothed values and its variance must therefore be combined with that of the individual experiments (0.032 percent). The results indicate that the total imprecision in resistivity is approximately 0.08 percent.

\subsection{Summary of Error Estimates}

Based on detailed analysis of identifiable random and systematic errors of each variable given in the previous sections, errors in properties are estimated. A summary of the imprecision and inaccuracy of measured and computed quantities is presented in table 12.

TABLE 12. Imprecision and inaccuracy of measured and computed quantities

\begin{tabular}{|c|c|c|}
\hline Quantity & $\begin{array}{c}\text { Imprecision } \\
\%\end{array}$ & $\begin{array}{c}\text { Inaccuracy } \\
\%\end{array}$ \\
\hline Temperature...... & $0.02(0.5 \mathrm{~K})$ & $\left\{\begin{array}{l}0.2(4 \mathrm{~K}) \text { at } 2000 \mathrm{~K} \\
0.25(7 \mathrm{~K}) \text { at } 2800 \mathrm{~K}\end{array}\right.$ \\
\hline Voltage................. & 0.02 & 0.05 \\
\hline Current............................ & .03 & .06 \\
\hline Power................. & .04 & .08 \\
\hline Resistance............ & .04 & .08 \\
\hline Length......... & .04 & .08 \\
\hline Weight.................... & .01 & .1 \\
\hline Density............................. & .02 & .1 \\
\hline Heat Capacity..... & .6 & $\left\{\begin{array}{l}2 \text { at } 2000 \mathrm{~K} \\
3\end{array}\right.$ \\
\hline Resistivity.. & .08 & $\begin{array}{c}(3 \text { at } 2800 \mathrm{~K} \\
0.5\end{array}$ \\
\hline Hem. Total Emittance......... & 1 & 3 \\
\hline Norm. Spectral Emittance. & 0.2 & 2 \\
\hline
\end{tabular}

Uncertainty in the heating rate is the major contribution to the total error in heat capacity. The uncertainty in heating rate is related primarily to the temperature errors. The electrical resistivity is dependent primarily on uncertainties in temperature and dimensions and, to a lesser extent, on uncertainties in voltage and current measurements. The major source of error in total hemispherical emittance is due to the uncertainty in the ratio of heating rate to cooling rate, while in the case of normal spectral emittance, uncertainty in temperature (through uncertainties in blackbody quality and scattered light correction) plays the most important role.

\section{General Discussion and Conclusions}

Since the interpretation of results for measured properties is given in detail in section 5, and since comparison of results of the present work with those in the literature is presented in section 6 , this section will be confined to discussion of other subjects directly or indirectly related to the high-speed measurement of properties at high temperatures.

Whether a specimen is under thermodynamic equilibrium while measurements are taken during dynamic heating and cooling periods may be determined by considering the relaxation times of various rate processes. In pure electrical conductors the main relaxation process is due to electron-phonon interactions. For metals at room temperature the relaxation time of this process is estimated to be less than $10^{-12} \mathrm{~s}$. Since relaxation time is directly proportional to electrical conductivity and since the latter decreases with increasing temperature, it takes a longer time to establish thermal equilibrium at high temperatures. The variation of electrical conductivity in metallic elements between room temperature and the melting point is within a factor of 100; therefore, relaxation time in metals at high temperatures is of the order of $10^{-10} \mathrm{~s}$. Thus, in experiments of millisecond and even microsecond resolution the electronic and vibrational states of the specimen can be considered to be in thermodynamic equilibrium during the time of measurements.

The equilibrium concentration of vacancies in the lattice has been discussed in section 5 , and its estimated contribution to heat capacity is given in table 7 . These estimates may be considered to be an indication of the upper limit of the change in the heat capacity if the concentration departs from equilibrium values during a rapid heating or cooling process. From this, one may conclude that departures of heat capacity from equilibrium values are less than the imprecision of the measurements throughout most of the temperature range.

Information concerning relaxation times for vacancy equilibrium is not readily obtainable; but since the mechanism is related to that of diffusion, the relaxation time is an exponential function of temperature. The magnitude of vacancy relaxation time as observed in quenching experiments at lower temperatures and extrapolated up to the melting point may be of the order of a millisecond for molybdenum in the temperature range 2500 to $2800 \mathrm{~K}$. The vacancy kinetics of molybdenum has not been investigated sufficiently to permit reliable estimates.

The difference between the measured weight loss of the specimen and the computed weight loss due to evaporation, which in all cases was less than 0.01 percent per experiment, is attributed to oxidation followed by evaporation of the oxide. It can be noted that at very high temperatures actual weight loss was very close to that computed for evaporation, while at low and medium temperatures the weight loss was probably primarily due to oxidation.

Molybdenum forms primarily two oxides, $\mathrm{MoO}_{2}$ and $\mathrm{MoO}_{3}$. Studies reported in the literature $[39,60]$ indicate that the oxidation rate of molybdenum may be represented by a parabolic function in time at moderately high temperatures and by a linear function at temperatures above $1000 \mathrm{~K}$ because of the volatility 
of $\mathrm{MoO}_{3}$. Thus, above about $1000 \mathrm{~K}$ oxidation is accompanied by a loss in specimen weight.

The results for electrical resistivity (high and ambient temperature) and residual electrical resistivity ratio indicate a reduction in impurity content or in other imperfections at the end of the experiments. Chemical analysis did not show any detectable change in the impurity content between the initial and final states of the specimen. This fact may be partly attributed to the low sensitivity of the analysis.

It has been reported $[25,56]$ that at high temperatures certain impurities in a solid can diffuse to the surface and evaporate thus causing partial purification of the specimen and the generation of clean surfaces. Several investigators $[9,24,58,75]$ have observed that small amounts of oxygen present in the system may react with the carbon impurities in the specimen (refractory metals) and produce $\mathrm{CO}$ and $\mathrm{CO}_{2}$.

In conclusion, changes in impurity content, grain growth, or departures of vacancy concentrations from equilibrium, discussed above or earlier in the text, all together may conceivably account for the observed changes of 1.3 to 2.2 percent in heat capacity between the first and second series of measurements. No other satisfactory explanation has been found. The results of the second series are recommended to represent the properties of molybdenum.

Experimental results reported in this study have shown the feasibility of accurate measurement of heat capacity and electrical resistivity of electrical conductors at high temperatures (above $2000 \mathrm{~K}$ ) by a pulse method of millisecond resolution. The results also indicate that under proper surface and environmental conditions the technique allows the measurement of total hemispherical and normal spectral emittances. At $2000 \mathrm{~K}$ the accuracy of measured properties by this method is estimated to be about the same as that obtained by conventional methods. At temperatures above $2500 \mathrm{~K}$ it surpasses any other method now known. In fact, high-speed measurements play a unique role in research at very high temperatures where conventional techniques cannot be used because of excessive heat losses, evaporation, chemical reactions, mechanical instability, etc. Thus, dynamic measurement techniques become an important and very attractive tool in the study of refractory metals and their alloys, as well as other high melting electrically conducting substances. Another distinct advantage of this technique is that it permits the measurement of several properties simultaneously.

The authors extend their appreciation to G. M. Foley of Leeds and Northrup Co. (also guest worker at NBS) for his research on the millisecond pyrometer and for his advice and assistance in connection with the operation of the pyrometer.

\section{Appendix}

TABLE A-1. Experimental results on heat capacity and electrical resistivity of molybdenum (first series)

\begin{tabular}{|c|c|c|c|}
\hline $\begin{array}{c}\text { Range and } \\
\text { Exp. No. }\end{array}$ & $\begin{array}{l}\mathrm{T} \\
\mathrm{K}\end{array}$ & $\mathrm{J} \mathrm{mol}^{-1} \mathrm{~K}^{-1}$ & $\stackrel{\rho}{\rho} 10^{-8} \Omega \mathrm{m}$ \\
\hline Low & & & \\
\hline $\begin{array}{l}246 \\
246 \\
246 \\
246 \\
246 \\
246\end{array}$ & $\begin{array}{l}1900 \\
1940 \\
1980 \\
2020 \\
2060 \\
2100\end{array}$ & $\begin{array}{l}34.28 \\
34.83 \\
35.38 \\
35.93 \\
36.47 \\
37.01\end{array}$ & $\begin{array}{l}49.68 \\
50.92 \\
52.18 \\
53.45 \\
54.73 \\
56.02\end{array}$ \\
\hline $\begin{array}{l}247 \\
247 \\
247 \\
247 \\
247 \\
247\end{array}$ & $\begin{array}{l}1900 \\
1940 \\
1980 \\
2020 \\
2060 \\
2100\end{array}$ & $\begin{array}{l}34.43 \\
34.89 \\
35.34 \\
35.79 \\
36.22 \\
36.65\end{array}$ & $\begin{array}{l}49.68 \\
50.93 \\
52.19 \\
53.45 \\
54.72 \\
55.99\end{array}$ \\
\hline $\begin{array}{l}248 \\
248 \\
248 \\
248 \\
248 \\
248\end{array}$ & $\begin{array}{l}1900 \\
1940 \\
1980 \\
2020 \\
2060 \\
2100\end{array}$ & $\begin{array}{l}34.15 \\
34.69 \\
35.23 \\
35.77 \\
36.30 \\
36.83\end{array}$ & $\begin{array}{l}49.67 \\
50.91 \\
52.16 \\
53.43 \\
54.70 \\
55.98\end{array}$ \\
\hline $\begin{array}{l}251 \\
251 \\
251 \\
251 \\
251 \\
251\end{array}$ & $\begin{array}{l}1900 \\
1940 \\
1980 \\
2020 \\
2060 \\
2100\end{array}$ & $\begin{array}{l}34.21 \\
34.77 \\
35.33 \\
35.88 \\
36.43 \\
36.98\end{array}$ & $\begin{array}{l}49.69 \\
50.93 \\
52.19 \\
53.45 \\
54.73 \\
56.02\end{array}$ \\
\hline $\begin{array}{l}252 \\
252 \\
252 \\
252 \\
252 \\
252\end{array}$ & $\begin{array}{l}1900 \\
1940 \\
1980 \\
2020 \\
2060 \\
2100\end{array}$ & $\begin{array}{l}34.45 \\
34.89 \\
35.32 \\
35.73 \\
36.14 \\
36.53\end{array}$ & $\begin{array}{l}49.69 \\
50.94 \\
52.19 \\
53.46 \\
54.73 \\
56.00\end{array}$ \\
\hline $\begin{array}{l}253 \\
253 \\
253 \\
253 \\
253 \\
253\end{array}$ & $\begin{array}{l}1900 \\
1940 \\
1980 \\
2020 \\
2060 \\
2100\end{array}$ & $\begin{array}{l}34.80 \\
35.15 \\
35.48 \\
35.80 \\
36.11 \\
36.40\end{array}$ & $\begin{array}{l}49.65 \\
50.91 \\
52.18 \\
53.45 \\
54.72 \\
56.01\end{array}$ \\
\hline Medium & & & \\
\hline $\begin{array}{l}223 \\
223 \\
223 \\
223 \\
223 \\
223 \\
223\end{array}$ & $\begin{array}{l}2000 \\
2040 \\
2080 \\
2120 \\
2160 \\
2200 \\
2240\end{array}$ & $\begin{array}{l}35.52 \\
36.07 \\
36.61 \\
37.15 \\
37.68 \\
38.21 \\
38.73\end{array}$ & $\begin{array}{l}52.86 \\
54.12 \\
55.39 \\
56.67 \\
57.96 \\
59.26 \\
60.57\end{array}$ \\
\hline $\begin{array}{l}224 \\
224 \\
224 \\
224 \\
224 \\
224\end{array}$ & $\begin{array}{l}2000 \\
2040 \\
2080 \\
2120 \\
2160 \\
2200\end{array}$ & $\begin{array}{l}35.71 \\
36.19 \\
36.65 \\
37.11 \\
37.56 \\
37.99\end{array}$ & $\begin{array}{l}52.86 \\
54.13 \\
55.41 \\
56.69 \\
57.96 \\
59.24\end{array}$ \\
\hline $\begin{array}{l}225 \\
225 \\
225 \\
225 \\
225 \\
225 \\
225\end{array}$ & $\begin{array}{l}2000 \\
2040 \\
2080 \\
2120 \\
2160 \\
2200 \\
2240\end{array}$ & $\begin{array}{l}35.89 \\
36.33 \\
36.76 \\
37.18 \\
37.58 \\
37.97 \\
38.36\end{array}$ & $\begin{array}{l}52.87 \\
54.15 \\
55.43 \\
56.71 \\
57.99 \\
59.27 \\
60.55\end{array}$ \\
\hline
\end{tabular}


TABLE A-1. Experimental results on heat capacity and electrical resistivity of molybdenum (first series) - Con.

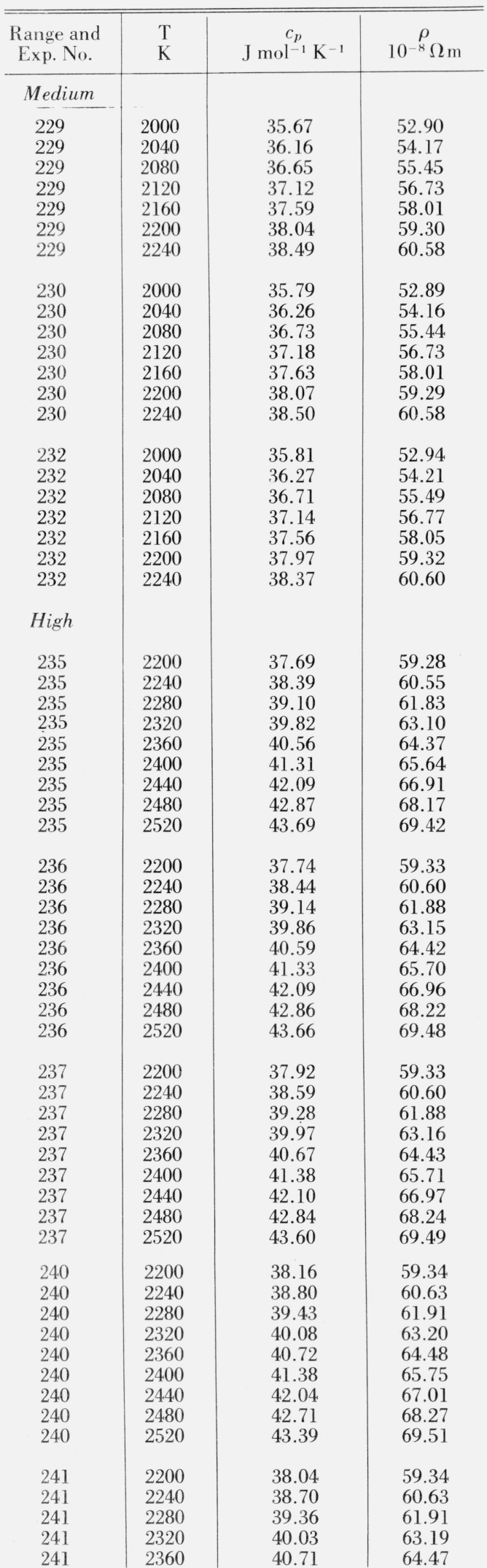

TABLE A-1. Experimental results on heat capacity and electrical resistivity of molybdenum (first series) - Con.

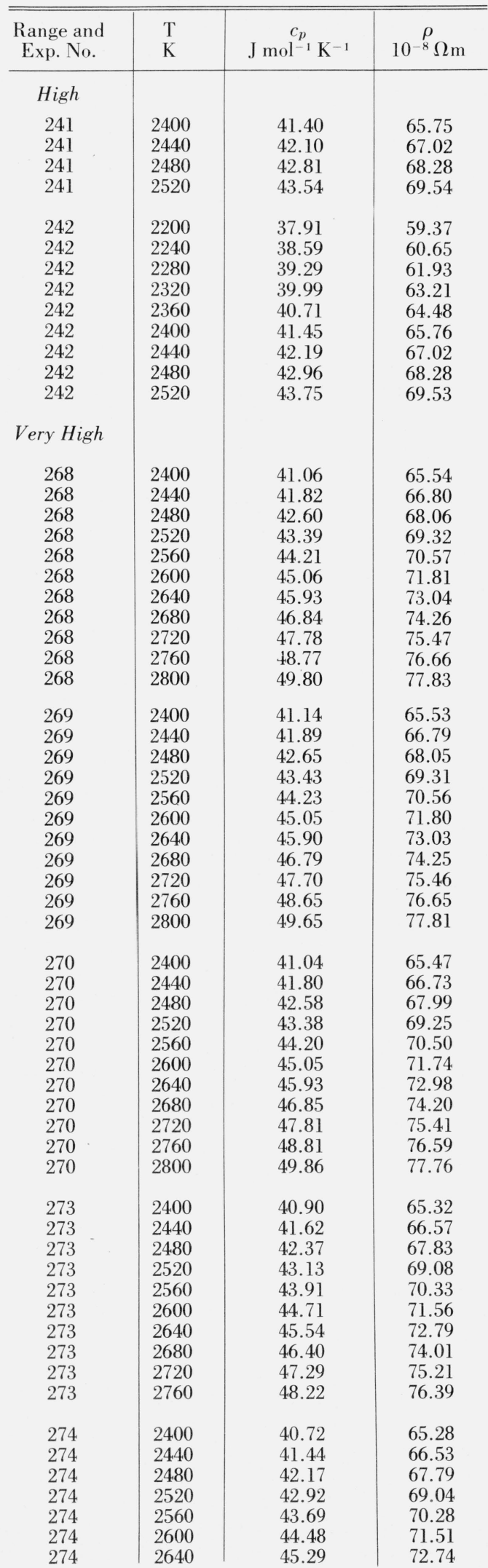


TABLE A-1. Experimental results on heat capacity and electrical resistivity of molybdenum (first series) - Con.

\begin{tabular}{c|c|c|c}
\hline \hline $\begin{array}{c}\text { Range and } \\
\text { Exp. No. }\end{array}$ & $\mathrm{T}$ & $\begin{array}{c}c_{p} \\
\mathrm{~K}\end{array}$ & $\begin{array}{c}\rho \\
\mathrm{J} \mathrm{mol}^{-1} \mathrm{~K}^{-1}\end{array}$ \\
\hline & & & \\
\hline Very High & & & \\
274 & 2680 & 46.12 & 73.95 \\
274 & 2720 & 46.98 & 75.14 \\
274 & 2760 & 47.88 & 76.31 \\
274 & 2800 & 48.81 & 77.46 \\
& & & \\
275 & 2400 & 40.51 & 65.27 \\
275 & 2440 & 41.23 & 66.51 \\
275 & 2480 & 41.97 & 67.75 \\
275 & 2520 & 42.73 & 68.98 \\
275 & 2560 & 43.51 & 70.22 \\
275 & 2600 & 44.31 & 71.44 \\
275 & 2640 & 45.13 & 72.66 \\
275 & 2680 & 45.98 & 73.87 \\
275 & 2720 & 46.86 & 75.06 \\
275 & 2760 & 47.78 & 76.25 \\
275 & 2800 & 48.74 & 77.41 \\
\hline
\end{tabular}

TABLE A-2. Experimental results on heat capacity and electrical resistivity of molybdenum (second series)

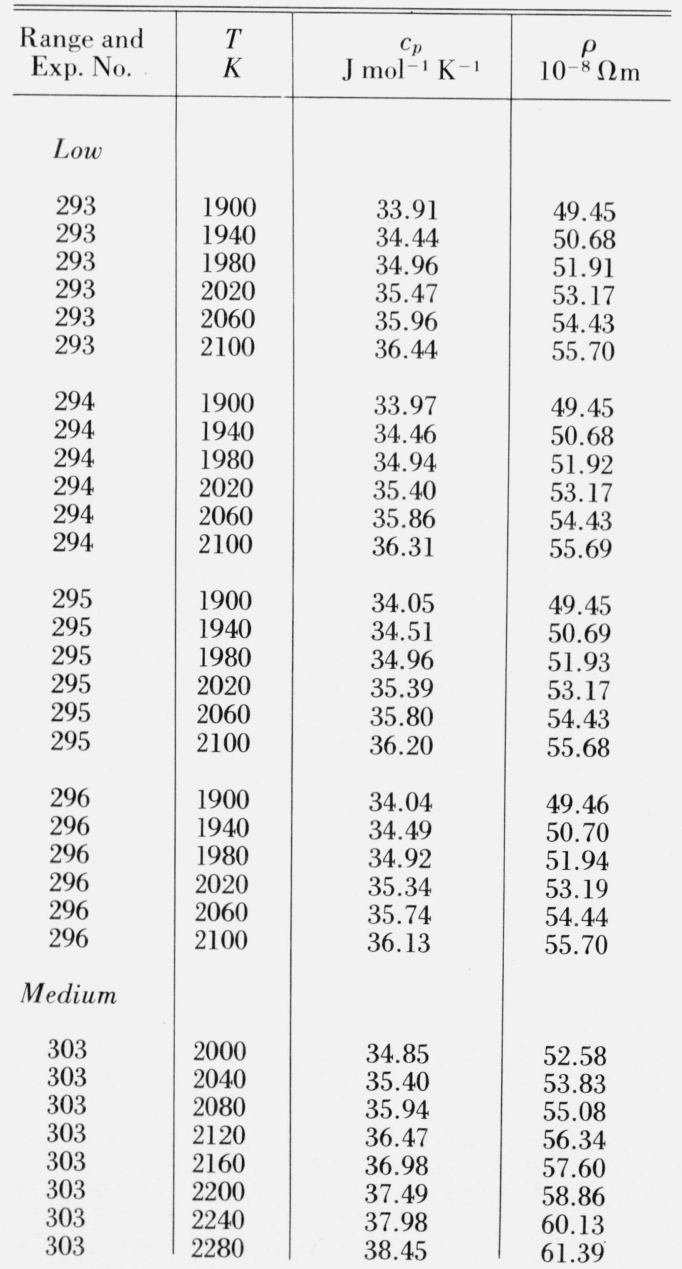

TABLE A-2. Experimental results on heat capacity and electrical resistivity of molybdenum (second series) - Continued

\begin{tabular}{|c|c|c|c|}
\hline $\begin{array}{l}\text { Range and } \\
\text { Exp. No. }\end{array}$ & $\begin{array}{l}T \\
K\end{array}$ & $\begin{array}{c}c_{p} \\
\mathrm{~J} \mathrm{~mol}^{-1} \mathrm{~K}^{-1}\end{array}$ & $\stackrel{\rho}{\rho} \Omega \mathrm{m}$ \\
\hline \multicolumn{4}{|l|}{ Medium } \\
\hline $\begin{array}{l}304 \\
304 \\
304 \\
304 \\
304 \\
304 \\
304 \\
304\end{array}$ & $\begin{array}{l}2000 \\
2040 \\
2080 \\
2120 \\
2160 \\
2200 \\
2240 \\
2280\end{array}$ & $\begin{array}{l}35.01 \\
35.53 \\
36.04 \\
36.53 \\
37.01 \\
37.48 \\
37.93 \\
38.36\end{array}$ & $\begin{array}{l}52.59 \\
53.84 \\
55.09 \\
56.35 \\
57.61 \\
58.88 \\
60.15 \\
61.42\end{array}$ \\
\hline $\begin{array}{l}305 \\
305 \\
305 \\
305 \\
305 \\
305 \\
305 \\
305\end{array}$ & $\begin{array}{l}2000 \\
2040 \\
2080 \\
2120 \\
2160 \\
2200 \\
2240 \\
2280\end{array}$ & $\begin{array}{l}35.05 \\
35.57 \\
36.07 \\
36.55 \\
37.03 \\
37.48 \\
37.93 \\
38.35\end{array}$ & $\begin{array}{l}52.59 \\
53.84 \\
55.10 \\
56.36 \\
57.62 \\
58.88 \\
60.15 \\
61.41\end{array}$ \\
\hline $\begin{array}{l}306 \\
306 \\
306 \\
306 \\
306 \\
306 \\
306 \\
306\end{array}$ & $\begin{array}{l}2000 \\
2040 \\
2080 \\
2120 \\
2160 \\
2200 \\
2240 \\
2280\end{array}$ & $\begin{array}{l}34.99 \\
35.53 \\
36.06 \\
36.57 \\
37.07 \\
37.56 \\
38.04 \\
38.50\end{array}$ & $\begin{array}{l}52.60 \\
53.84 \\
55.10 \\
56.36 \\
57.62 \\
58.89 \\
60.17 \\
61.45\end{array}$ \\
\hline High & & & \\
\hline $\begin{array}{l}315 \\
315 \\
315 \\
315 \\
315 \\
315 \\
315 \\
315 \\
315\end{array}$ & $\begin{array}{l}2200 \\
2240 \\
2280 \\
2320 \\
2360 \\
2400 \\
2440 \\
2480 \\
2520\end{array}$ & $\begin{array}{l}37.22 \\
37.87 \\
38.52 \\
39.16 \\
39.81 \\
40.44 \\
41.08 \\
41.71 \\
42.34\end{array}$ & $\begin{array}{l}58.73 \\
59.99 \\
61.26 \\
62.52 \\
63.79 \\
65.04 \\
66.30 \\
67.55 \\
68.79\end{array}$ \\
\hline $\begin{array}{l}316 \\
316 \\
316 \\
316 \\
316 \\
316 \\
316 \\
316 \\
316\end{array}$ & $\begin{array}{l}2200 \\
2240 \\
2280 \\
2320 \\
2360 \\
2400 \\
2440 \\
2480 \\
2520\end{array}$ & $\begin{array}{l}37.35 \\
37.99 \\
38.62 \\
39.25 \\
39.87 \\
40.49 \\
41.10 \\
41.71 \\
42.31\end{array}$ & $\begin{array}{l}58.76 \\
60.02 \\
61.29 \\
62.55 \\
63.81 \\
65.07 \\
66.32 \\
67.57 \\
68.81\end{array}$ \\
\hline $\begin{array}{l}317 \\
317 \\
317 \\
317 \\
317 \\
317 \\
317 \\
317 \\
317\end{array}$ & $\begin{array}{l}2200 \\
2240 \\
2280 \\
2320 \\
2360 \\
2400 \\
2440 \\
2480 \\
2520\end{array}$ & $\begin{array}{l}37.34 \\
37.98 \\
38.62 \\
39.25 \\
39.87 \\
40.49 \\
41.11 \\
41.72 \\
42.32\end{array}$ & $\begin{array}{l}58.77 \\
60.03 \\
61.30 \\
62.56 \\
63.83 \\
65.09 \\
66.34 \\
67.59 \\
68.84\end{array}$ \\
\hline $\begin{array}{l}318 \\
318 \\
318 \\
318 \\
318 \\
318 \\
318 \\
318 \\
318\end{array}$ & $\begin{array}{l}2200 \\
2240 \\
2280 \\
2320 \\
2360 \\
2400 \\
2440 \\
2480 \\
2520\end{array}$ & $\begin{array}{l}37.24 \\
37.90 \\
38.56 \\
39.22 \\
39.88 \\
40.54 \\
41.19 \\
41.85 \\
42.50\end{array}$ & $\begin{array}{l}58.79 \\
60.06 \\
61.32 \\
62.59 \\
63.85 \\
65.11 \\
66.36 \\
67.61 \\
68.86\end{array}$ \\
\hline
\end{tabular}


TABLE A-2. Experimental results on heat capacity and electrical resistivity of molybdenum (second series) - Continued

\begin{tabular}{c|c|c|c}
\hline \hline Range and & $T$ & $c_{p}$ & $\begin{array}{c}\rho \\
\text { Exp. No. }\end{array}$ \\
& $K$ & $\mathrm{~J} \mathrm{~mol}^{-1} \mathrm{~K}^{-1}$ & $10^{-8} \mathrm{~m}$ \\
\hline & & & \\
Very High & & & \\
324 & 2400 & 40.44 & 64.97 \\
324 & 2440 & 41.17 & 66.22 \\
324 & 2480 & 41.90 & 67.47 \\
324 & 2520 & 42.63 & 68.72 \\
324 & 2560 & 43.37 & 69.96 \\
324 & 2600 & 44.11 & 71.19 \\
324 & 2640 & 44.86 & 72.41 \\
324 & 2680 & 45.62 & 73.61 \\
324 & 2720 & 46.39 & 74.81 \\
& & & \\
325 & 2400 & 40.46 & 64.99 \\
325 & 2440 & 41.19 & 66.25 \\
325 & 2480 & 41.92 & 67.51 \\
325 & 2520 & 42.66 & 68.76 \\
325 & 2560 & 43.40 & 69.99 \\
325 & 2600 & 44.15 & 71.22 \\
325 & 2640 & 44.90 & 72.44 \\
325 & 2680 & 45.67 & 73.65 \\
325 & 2720 & 46.44 & 74.84 \\
325 & 2760 & 47.22 & 76.01 \\
325 & 2800 & 48.02 & 77.16 \\
& & & \\
326 & 2400 & 40.40 & 65.00 \\
326 & 2440 & 41.15 & 66.26 \\
326 & 2480 & 41.91 & 67.52 \\
326 & 2520 & 42.68 & 68.76 \\
326 & 2560 & 43.46 & 70.00 \\
326 & 2600 & 44.24 & 71.24 \\
326 & 2640 & 45.04 & 72.46 \\
326 & 2680 & 45.85 & 73.67 \\
326 & 2720 & 46.68 & 74.86 \\
326 & 2760 & 47.52 & 76.04 \\
326 & 2800 & 48.39 & 77.19 \\
327 & 2400 & 40.42 & 65.02 \\
327 & 2440 & 41.18 & 66.28 \\
327 & 2480 & 41.95 & 67.54 \\
327 & 2520 & 42.73 & 68.79 \\
327 & 2560 & 43.51 & 70.03 \\
327 & 2600 & 44.31 & 71.26 \\
327 & 2640 & 45.12 & 72.49 \\
327 & 2680 & 45.94 & 73.70 \\
327 & 2720 & 46.78 & 74.90 \\
327 & 2760 & 47.64 & 76.09 \\
\hline & & &
\end{tabular}

TABLE A-3. Experimental results on normal spectral emittance of molyb denum at $\lambda=650 \mathrm{~nm}$ (second series)

\begin{tabular}{|c|c|c|}
\hline Exp. No. & $\begin{array}{l}T \\
\mathrm{~K}\end{array}$ & $\epsilon_{N, \lambda}$ \\
\hline 288 & 1833 & 0.3341 \\
\hline 288 & 1847 & .3324 \\
\hline 288 & 1862 & .3314 \\
\hline 288 & 1876 & .3309 \\
\hline 288 & 1896 & .3305 \\
\hline 288 & 1910 & .3310 \\
\hline 288 & 1924 & .3318 \\
\hline 297 & 2011 & .3300 \\
\hline 297 & 2030 & .3301 \\
\hline 297 & 2041 & .3300 \\
\hline 297 & 2057 & .3300 \\
\hline 297 & 2090 & .3302 \\
\hline 297 & 2104 & .3303 \\
\hline 297 & 2123 & .3302 \\
\hline 307 & 2165 & .3296 \\
\hline 307 & 2184 & .3292 \\
\hline 307 & 2203 & .3288 \\
\hline 307 & 2222 & .3283 \\
\hline 307 & 2240 & .3278 \\
\hline 307 & 2259 & .3273 \\
\hline 307 & 2277 & .3268 \\
\hline 319 & 2401 & .3252 \\
\hline 319 & 2418 & .3250 \\
\hline 319 & 2434 & .3248 \\
\hline 319 & 2451 & .3246 \\
\hline 319 & 2467 & .3245 \\
\hline 319 & 2483 & .3244 \\
\hline 319 & 2500 & .3243 \\
\hline 328 & 2606 & .3235 \\
\hline 328 & 2628 & .3232 \\
\hline 328 & 2650 & .3230 \\
\hline 328 & 2672 & .3228 \\
\hline 328 & 2694 & .3226 \\
\hline 328 & 2715 & .3224 \\
\hline 328 & 2736 & .3222 \\
\hline 328 & 2757 & .3219 \\
\hline 328 & 2777 & .3216 \\
\hline
\end{tabular}


TABLE A-4. Experimental results on hemispherical total emittance of molybdenum (first and second series)

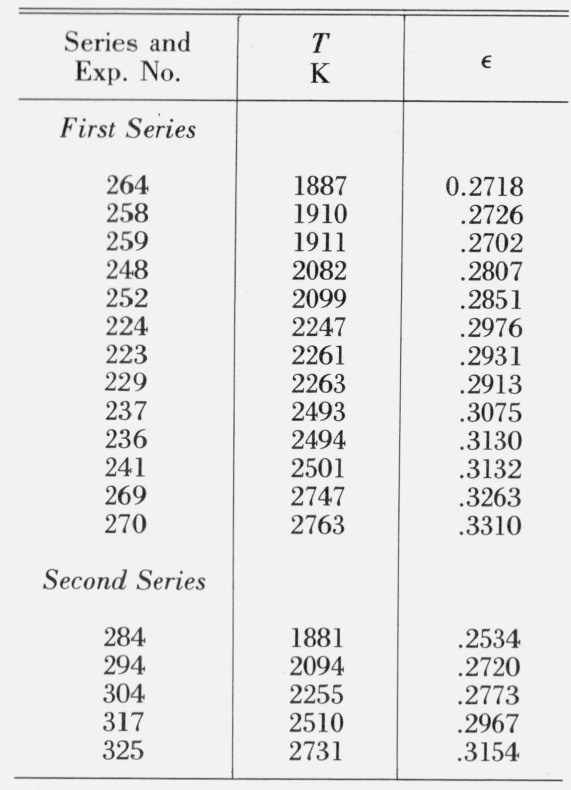

\section{References}

[1] Abbott, G. L., N. J. Alvares, and W. J. Parker, WADD-TR61-94, II (1962).

[2] Allen, R. D., L. F. Glasier, Jr., and P. L. Jordan, J. Appl. Phys., 31, 1382 (1960).

[3] Amonenko, V. M., P. N. V'yugov, and V. S. Gumenyuk, High Temperature 2, 22 (1964).

[4] Argent, B. B., and J. G. C. Milne, The physical properties of niobium, Tantalum, Molybdenum, and Tungsten, in Niobium, Tantalum, Molybdenum and Tungsten, p. 162, A. G. Quarrell, Ed. (Elsevier, Amsterdam, 1961).

[5] Askwyth, W. H., R. J. Yahes, R. D. House, and G. Mikk, NASA-CR-56496 (1964).

[6] Avramescu, A., Z. Tech. Physik 20, 213 (1939).

[7] Barnes, B. T., J. Opt. Soc. Am. 56, 1546 (1966).

[8] Baxter, H. W., Nature 153, 316 (1944).

[9] Becker, J. A., E. J. Becker, and R. G. Brandes, J. Appl. Phys. 32, 411 (1961).

[10] Beckett, C. W., and A. Cezairliyan, High-Speed Thermodynamic Measurements and Related Techniques, in Experimental Thermodynamics, Vol. I, Calorimetry of Non-Reacting Systems, p. 551 J. P. McCullough and D. W. Scott, Eds. (Butterworths, London, 1968).

[11] Carslaw, H. S., and J. C. Jaeger, Conduction of Heat in Solids (Oxford University Press, Oxford, 1959).

[12] Cezairliyan, A., A High-Speed (Millisecond) Method for the simultaneous measurement of enthalpy, specific heat, and resistivity of electrical conductors at high temperatures, in Advances in Thermophysical Properties at Extreme Temperatures and Pressures, p. 253 ASME, New York, (1965).

[13] Compt. Rend. of the 21st Conference of the International Union of Pure and Applied Chemistry, Montreal (1961), Report of the Committee on Atomic Weights, pp. 284-327.

[14] DeSorbo, W., Phys. Rev. 117, 444 (1960).

[15] DeVos, J. C., Physica 20, 669 (1954).

[16] Douglas, T. B., J. Res. Nat. Bur. Stand. (U.S.), 73A (Phys. and Chem), No. 5, 451 (Sept.-Oct. 1969).

[17] DuBridge, L. A., and W. W. Roehr, Phys. Rev. 42, 52 (1932).

[18] Edwards, J. W., R. Speiser, and H. L. Johnston, J. Appl. Phys. 22, 424 (1951).

[19] Feith, A. D., Measurement of the Thermal Conductivity and Electrical Resistivity of Molybdenum, General Electric Report (GE-TM 65-10-1), (1965).
[20] Foley, G. M., High-Speed Optical Pyrometer, in preparation.

[21] Grew, K. E., Proc. Roy. Soc. (London) 145, 509 (1934).

[22]. Grover, F. W., Inductance Calculations (Van Nostrand, New York, 1946).

[23] Gshneidner, K. A., Physical Properties and Interrelationships of Metallic and Semimetallic Elements, in Solid State Physics, Vol. 16, p. 275 F. Seitz and D. Turnbull, Eds. (Academic Press, New York, 1965).

[24] Haas, T. W., Res. Rev. (Off. of Aerospace Research-USAF) 5, 3 (Apr. 1966).

[25] Hagstrum, H. D., and C. D'Amico, J. Appl. Phys. 31, 715 (1960).

[26] Holder, J., and A. V. Granato, Phys. Rev. 182, 729 (1969).

[27] Horowitz, M., and J. G. Daunt, Phys. Rev., 91, 1099 (1953).

[28] House, R. D., G. J. Lyons, and W. H. Askwyth, Measurement of Spectral Normal Emittance of Materials Under Simulated Spacecraft Powerplant Operating Conditions, in Measurement of Thermal Radiation Properties of Solids, J. C. Richmond, Ed., NASA, Washington, p. 343 (1963).

[29] International Practical Temperature Scale of 1968, Metrologia 5, 35 (1969).

[30] Jaeger, F. M., and W. A. Veenstra, Rec. Trav. Chim. 53, 677 (1934).

[31] JANAF Thermochemical Tables (Second Addendum), Clearinghouse for Federal Scientific and Technical Information, U.S. Department of Commerce, PB 168 370-2 (1967).

[32] Jones, H. A., I. Langmuir, and G. M. J. MacKay, Phys. Rev. 30, 201 (1927).

[33] Killeffer, D. H., and A. Linz, Molybdenum Compounds, p. 14 (Interscience Publishers, New York, 1952).

[34] Kirby, R. K., Thermal Expansion, in American Institute of Physics Handbook, sect. 4, p. 64 (McGraw-Hill, Book Co., New York, 1963)

[35] Kirillin, V. A., A. E. Sheindlin, and V. Y. Chekhovskoi, Int. J. Heat Mass Transfer 5, 1 (1962).

[36] Kirillin, V. A., A. E. Sheindlin, V. Y. Chekhovskoi, and V. A. Petrov, Enthalpy and Heat Capacity of Molybdenum at Extremely High Temperatures, in Proc. of Fourth Symposium on Thermophysical Properties, J. R. Moszynski, Ed., ASME, New York, p. 54 (1968).

[37] Kollie, T. G., Rev. Sci. Instr. 38, 1452 (1967).

[38] Kraftmacher, Y. A., Physica Status Solidi 5, K48 (1964).

[39] Kubaschewski, O., and B. E. Hopkins, Oxidation Mechanisms of Niobium, Tantalum, Molybdenum and Tungsten, in Niobium, Tantalum, Molybdenum, and Tungsten, p. 181 A. G. Quarrell, Ed. (Elsevier, Amsterdam, 1961).

[40] Kurrelmeyer, B., W. H. Mais, and E. H. Green, Rev. Sci. Instr. 14, 349 (1943).

[41] Lapp, E., Ann. Chimie et Physique 12, 442 (1929).

[42] Lazareva, L. S., P. B. Kantor, and V. V. Kandyba, Phys. Metals and Metallog. (USSR), 11, 133 (1961).

[43] Lowenthal, G. C., Aust. J. Phys. 16, 47 (1963).

[44] McLean, D., Grain Boundaries in Metals (Oxford University Press, Oxford, 1957).

[45] Meakin, J. D., A. Lawley, and R. C. Koo, Vacancy Loops in Quenched Molybdenum, in Lattice Defects in Quenched Metals, p. 767 R. M. J. Cotterill, M. Doyama, J. J. Jackson, and M. Meshi, Eds. (Academic Press, New York, 1965).

[46] Morse, M. S., and A. Cezairliyan, High-Speed Digital Data Acquisition System for Thermodynamic Measurements, in preparation.

[47] Nathan, A. M., J. Appl. Phys. 22, 234 (1951).

[48] Osborn, R. H., J. Opt. Soc. Am. 31, 428 (1941).

[49] Pallister, P. R., J. Iron Steel Inst. 161, 87 (1949).

[50] Parker, R., Trans. Met. Soc. AIME 233, 1545 (1965).

[51] Pasternak, R. A., E. C. Fraser, B. B. Hansen, and H. U. D. Wiesendanger, Rev. Sci. Instr. 33, 1320 (1962).

[52] Pasternak, R. A., H. U. D. Wiesendanger, and B. B. Hansen, J. Appl. Phys. 34, 3416 (1963).

[53] Pochapsky, T. E., Acta Met. 1, 747 (1953).

[54] Pochapsky, T. E., Rev. Sci. Instr. 25, 238 (1954).

[55] Rasor, N. S., and J. D. McClelland, J. Phys. Chem. Solids 15, 17 (1960).

[56] Roberts, R. W., Brit. J. Appl. Phys. 14, 537 (1963).

[57] Rudkin, R. L., W. J. Parker, and R. J. Jenkins, Measurement of Thermal Properties of Metals at Elevated Temperatures, in Temperature, Its Measurement and Control in Science and Industry, Vol. III, C. M. Herzfeld, ed., Reinhold, New York, Part 2, p. 523 (1962). 
[58] Schlier, R. E., J. Appl. Phys. 29, 1162 (1958).

[59] Schultz, H., Quenching of Vacancies in Tungsten, in Lattice Defects in Quenched Metals, R. M. J. Cotterill, M. Doyama, J. J. Jackson, and M. Meshi, Eds., p. 761 (Academic Press, New York, 1965).

[60] Seybolt, A. U., Adv. in Phys. 12, 1 (1963).

[61] Simmons, R. O., and R. W. Balluffi, Phys. Rev. 125, 862 (1962).

[62] Simmons, R. O., and R. W. Balluffi, Phys. Rev. 129, 1533 (1963).

[63l Stanley, J. K., Electrical and Magnetic Properties of Metals, American Society for Metals, Metals Park, Ohio (1963).

[64] Stimson, H. F., J. Res. Nat. Bur. Stand. (U.S.), 65A (Phys. and Chem.) No. 3, 139 (May-June 1961).

[65] Taylor, R. E., and R. A. Finch, J. Less-Common Metals 6, 283 (1964).

[66] Taylor, R. E., private Communication (1964).
[67] Tietz, T. E., and J. W. Wilson, Behavior and Properties of Refractory Metals, p. 28 (Stanford University Press, California, 1965).

[68] Tye, R. P., J. Less-Common Metals 3, 13 (1961).

[69] Wallace, D. C., Phys. Rev. 120, 84 (1960).

[70] Wallace, D. C., P. H. Sidles, and G. C. Danielson, J. Appl. Phys. 31, 168 (1960).

[71] White, G. K., and S. B. Woods, Phil. Trans. Royal Soc. (London), 251, 273 (1959).

[72] Worthing, A. G., Phys. Rev. 12, 199 (1918).

[73] Worthing, A. G., Phys. Rev. 28, 190 (1926).

[74] Wright, R. W., Phys. Rev. 60, 465 (1941).

[75] Young, J. R., J. Appl. Phys. 30, 1671 (1959).

[76] Zhorov, G. A., High Temperature 5, 881 (1967).

(Paper 74Al-586) 